PROSOCIALITY PROMOTES WELL-BEING DURING COVID-19

RUNNING HEAD: PROSOCIALITY PROMOTES WELL-BEING DURING COVID-19

\title{
Prosocial behavior promotes positive emotion during the COVID-19 pandemic
}

Mohith M. Varma ${ }^{1,5}$, Danni Chen ${ }^{1,5}$, Xuanyi $\operatorname{Lin}^{1}$, Lara B. Aknin ${ }^{2}$ and Xiaoqing $\mathrm{Hu}^{1,3,4^{*}}$ 1, Department of Psychology, The University of Hong Kong

2, Department of Psychology, Simon Fraser University

3, The State Key Laboratory of Brain and Cognitive Sciences, The University of Hong Kong 4, HKU-Shenzhen Institute of Research and Innovation

5, M.M.V. and D.C. contributed equally

\section{Paper accepted at Emotion}

This is an uncorrected version of manuscript.

The final version may appear different.

OSF repository link: https://osf.io/e3kdr/

*Corresponding Author:

Xiaoqing $\mathrm{Hu}$

Department of Psychology, The University of Hong Kong,

Pokfulam, Hong Kong S.A.R. China

Email: xiaoqinghu@hku.hk 
PROSOCIALITY PROMOTES WELL-BEING DURING COVID-19

\begin{abstract}
The COVID-19 pandemic has raised concerns about humans' physical and mental wellbeing. In response, there has been an urgent "call to action" for psychological interventions that enhance positive emotion and psychological resilience. Prosocial behavior has been shown to effectively promote well-being, but is this strategy effective during a pandemic when ongoing apprehension for personal safety could acutely heighten self-focused concern? In two online pre-registered experiments $(N=1,623)$ conducted during the early stage of pandemic (April 2020), we examined this question by randomly assigning participants to engage in other- or self-beneficial action. For the first time, we manipulated whether prosocial behavior was related to the source of stress (COVID-19): participants purchased COVID-19-related (personal protective equipment, PPE) or COVID-19-unrelated items (food/writing supplies) for themselves or someone else. Consistent with pre-registered hypotheses, prosocial (vs. non-prosocial or proself) behavior led to higher levels of selfreported positive affect, empathy and social connectedness. Notably, we also found that psychological benefits were larger when generous acts were unrelated to COVID-19 (vs. related to COVID-19). When prosocial and proself spending involved identical COVID-19 PPEs items, prosocial behavior's benefits were detectable only on empathy and social connectedness, but not on post-task positive affect. These findings suggest that while there are boundary conditions to be considered, generous action offers one strategy to bolster wellbeing during the pandemic.
\end{abstract}

Keywords:

COVID-19, prosocial behavior, positive emotion, mental well-being, pandemic 
PROSOCIALITY PROMOTES WELL-BEING DURING COVID-19

\section{Prosocial behavior promotes positive emotion during the COVID-19 pandemic}

The COVID-19 pandemic has posed a significant threat to humans' physical and mental health (Gruber et al., 2020; Pfefferbaum \& North, 2020). People around the world have been inundated with COVID-19-related news and death-tolls. At the peak of COVID-19 isolation measures in April 2020, more than 3.9 billion people in 90 countries (Sandford, 2020) were affected by physical distancing or "stay at home" orders which helped to contain the virus but may have also precluded opportunities for meaningful social connections that could alleviate distress (Tull et al., 2020). The pressures of COVID-19 have been associated with sleep disturbance, substance abuse, anxiety, depression, and domestic violence (e.g., Altena et al., 2020; Humphreys et al., 2020; Holmes et al., 2020; Huang \& Zhao, 2020). Thus, it is of paramount importance to "develop novel interventions to protect mental wellbeing, including those based on positive mechanistically based components" (Holmes et al., 2020). Here, we examine the efficacy of one potential strategy: helping others.

Humans are an exceptionally prosocial species (Burkart et al., 2014). People frequently give their time, money, skill, blood and organs to help others (Aknin \& Whillans, 2020). In the United States alone, people donated $\$ 427.71$ billion to U.S. charities in 2018, according to Giving USA Annual Report on Philanthropy (2019). Impressively, prosocial tendencies have been shown to persist - and sometimes flourish - in emergency situations (e.g., Lowe \& Fothergill, 2003; Zaki, 2020). For instance, data collected in Louisiana following Hurricane Katrina captured prosocial behavior from diverse groups, such as hotels, hospitals, and communities in response to the catastrophe (Rodriguez et al., 2006). Similarly, after the 8.0 magnitude earthquake in Wenchuan, Sichuan, Chinese people in the highest areas of destruction displayed more generosity than those in less affected areas (Rao et al., 2011). This phenomenon, termed as "catastrophe compassion," has been observed during COVID-19; people have donated money, blood, and personal protection equipment to help 
PROSOCIALITY PROMOTES WELL-BEING DURING COVID-19

others. Frontline health workers have volunteered to join the "dirty team" to take care of those infected with COVID-19, and people have been providing emotional support to strangers on online message forums (e.g., Butler, 2020).

Selfless acts such as these can provide immeasurable assistance to recipients, but do helpers benefit from enacting prosocial behavior? A mounting body of evidence suggests that engaging in various forms of prosocial behavior can promote emotional well-being, which may stem from the positive experiences uniquely afforded by prosocial behavior, such as increased social connectedness and meaningfulness (Aknin et al., 2013; Aknin et al., 2020; Dunn et al., 2008; Dunn et al., 2014; Nelson et al., 2016; Klein, 2017; Poulin et al., 2013; Weinstein \& Ryan, 2010; see Curry et al., 2018; Hui et al., 2020 for meta-analyses). Despite this evidence, it is possible that the COVID-19 pandemic could undermine the positive relationship between prosocial behavior and emotional well-being. Specifically, COVID-19's imminent threat, exceptional spread and ever-increasing death toll may lead to reduced empathy, compassion fatigue and collapse, as well as greater ego-centric thinking (Cameron \& Payne, 2011; Todd, et al, 2015; Todd \& Simpson, 2016; Västfjäll et al., 2014). Indeed, past research on compassion collapse demonstrates that people exposed to greater numbers of disaster victims show lower levels of empathy toward others than those exposed to fewer victims (e.g., Cameron \& Payne, 2011; Galak et al., 2011; Kogut \& Rikov, 2005; Västfjäll et al., 2014). Moreover, higher levels of uncertainty increase ego-centric thinking (Todd, et al, 2015; Todd \& Simpson, 2016). These findings are important because past work also suggests that the emotional benefits of prosocial action may only be detectable among actors who have a high degree of care or concern for others (Hill \& Howell, 2014, see also Wiwad \& Aknin, 2017). Therefore, it is plausible that the threats imposed by COVID-19 may prioritize selfinterests, which might then eliminate or even reverse the emotional rewards of giving. 
PROSOCIALITY PROMOTES WELL-BEING DURING COVID-19

On the other hand, a large and growing body of research suggests that the emotional rewards of prosocial behavior are robust and detectable in a range of contexts. For example, prosocial behavior has been shown to increase positive affect in rich and poor countries around the globe (Aknin et al., 2013), in small-scale, rural societies (Aknin et al., 2015), in young children (Aknin et al., 2012), and among ex-offenders reporting elevated levels of antisocial tendencies (Hanniball et al., 2019). Building on this evidence, we hypothesized that prosocial behavior could enhance emotional well-being, even during an on-going pandemic when social isolation and mental stress are prevalent (Tull et al., 2020). Specifically, prosocial behavior's proximal outcomes such as increased social connectedness, meaningfulness could satisfy one's social and psychological needs and promote positive affect and well-being (e.g., Aknin et al., 2013; Aknin et al., 2018; Crocker et al., 2017; Hui et al., 2020). Consistent with this possibility, a recent study suggests that people reported experiencing higher levels of emotional well-being on days in which they engaged in more prosocial action during the COVID-19 pandemic (Sin et al., 2020). Thus, it seems plausible that prosocial action may also have a causal impact on well-being, even during the COVID19 pandemic - the largest collective trauma that most living humans have experienced (Fancourt et al., 2020; Rosenfeld et al., in press).

In addition to positive affect, research shows that prosocial behavior reduces negative psychological responses, such as distress, anxiety- and depression-related symptoms and even intrusive memories from lab-analogue traumatic experience (e.g., Cialdini \& Kenrick, 1976; Doré et al., 2017; Raposa et al, 2016; Varma \& Hu, in press; Wang et al., 2020). Here, we also examined whether prosocial behavior could alleviate subjective worry/fear and intrusive thoughts related to the pandemic. Excessive worry and intrusive thoughts are among the most common reactions to a traumatic event that could lead to anxiety and stress-related disorders (Bomyea \& Lang, 2016; Hu et al., 2017; Zoellner et al. 2012). Given that the 
PROSOCIALITY PROMOTES WELL-BEING DURING COVID-19

"altruism as hedonism" account suggests that helping can relieve one's own distress or sadness (Cialdini \& Kenrick, 1976; Raposa et al., 2016), we hypothesized that prosocial behavior could reduce negative affect and therefore intrusive thoughts (Marks et al., 2018; Varma \& $\mathrm{Hu}$, in press). However, past research shows that prosocial behavior is more strongly linked with positive emotions than negative emotions (Hui et al., 2020; Jebb et al., 2020; Kushlev et al., 2020 preprint). Furthermore, realistic imminent threats imposed by the on-going pandemic may render negative psychological reactions particularly salient and resistant to change. Therefore, it is possible that prosocial behavior may only enhance positive affect and positive psychological outcomes.

To examine these questions, we conducted two well-powered, preregistered experiments online between April 16-30, 2020, when the number of COVID-19 cases and fear of the virus rose dramatically worldwide. This timing was approximately one month after the World Health Organization declared the COVID-19 outbreak a pandemic on March 11, 2020 and the United States (US) administration declared COVID-19 a national emergency on March 13, 2020 (Keith \& Gharib, 2020). Infection cases within the US where our samples were drawn from - nearly doubled from 652,600 on April 15, 2020 to 1,100,000 on April 30, 2020 (John Hopkins University, 2020), suggesting that the pandemic was likely a central thought and salient context for many people. In both studies, participants reported their current affect and other psychological states before and after being randomly assigned to either a prosocial or a control condition (Experiment 1: a non-prosocial control condition; Experiment 2: proself conditions), allowing us to probe whether generous action promoted greater emotional and psychological well-being in the context of COVID-19. In Experiment 2, we also manipulated whether the prosocial or proself action was related to the current stressor - the COVID-19 pandemic - or not. Taken together, these studies allowed us to examine whether prosocial behavior 1) enhances positive affect and positive psychological 
PROSOCIALITY PROMOTES WELL-BEING DURING COVID-19

outcomes (e.g., meaningfulness, empathy), and 2) reduces negative affect and negative psychological reactions (fear/worry and intrusive thoughts related to COVID-19) during the COVID-19 pandemic. Moreover, Experiment 2 allowed us to examine whether the emotional rewards of prosocial action were moderated by the alignment between one's action and the current stressor (e.g., buying pandemic supplies vs. general supplies).

Materials, data, analytic code, and pre-registrations for both studies can be found at https://osf.io/e3kdr. This research was approved by the Human Research Ethics Committee of the University of Hong Kong. Participants provided informed consent prior to participation, and were debriefed upon completing the study. Participants were paid \$3 USD for their time.

\section{Experiment 1}

\section{Methods}

Participants. An a priori power analysis indicated that we required 398 participants to detect a small effect size of Cohen's $d=0.25$ with $\beta=80 \%$ and $\alpha=.05$ (one-tailed tests given our directional hypotheses). Our effect size estimate of $d=0.25$ was informed by previous pre-registered studies using a similar paradigm (Aknin et al., 2020; Hanniball et al., $2019, d s=0.36,0.15)$, and recent meta-analyses examining prosocial behavior's effect on well-being ( $\delta=0.28$ in Curry et al., 2018; $d=0.26$ in Hui et al., 2020). We pre-registered our intention to over-sample and collected data from 499 participants on Prolific Academic between April 16-17, 2020 (215 female, age: $M=26.78$ years old, $S D=6.08)$. The expected exclusion rate (20-25\%) was similar to other online research conducted during the COVID19 (see Pennycook et al., 2020).

Materials and Procedure. An overview of the experimental procedure is presented in Figure 1. Participants first completed a COVID-19 impact questionnaire which measured 1) their perceptions of COVID-19 infectiousness, death rates, and personal possibility of 
virus contraction; 2) their positive/negative affect in past seven days, 3) how COVID-19 had impacted their physical and mental health, work and social life, and distress levels, and 4) their intrusive thoughts related to COVID-19 in the past week. Participants also rated their alertness level on the Stanford Sleepiness Scale (SSS).

A

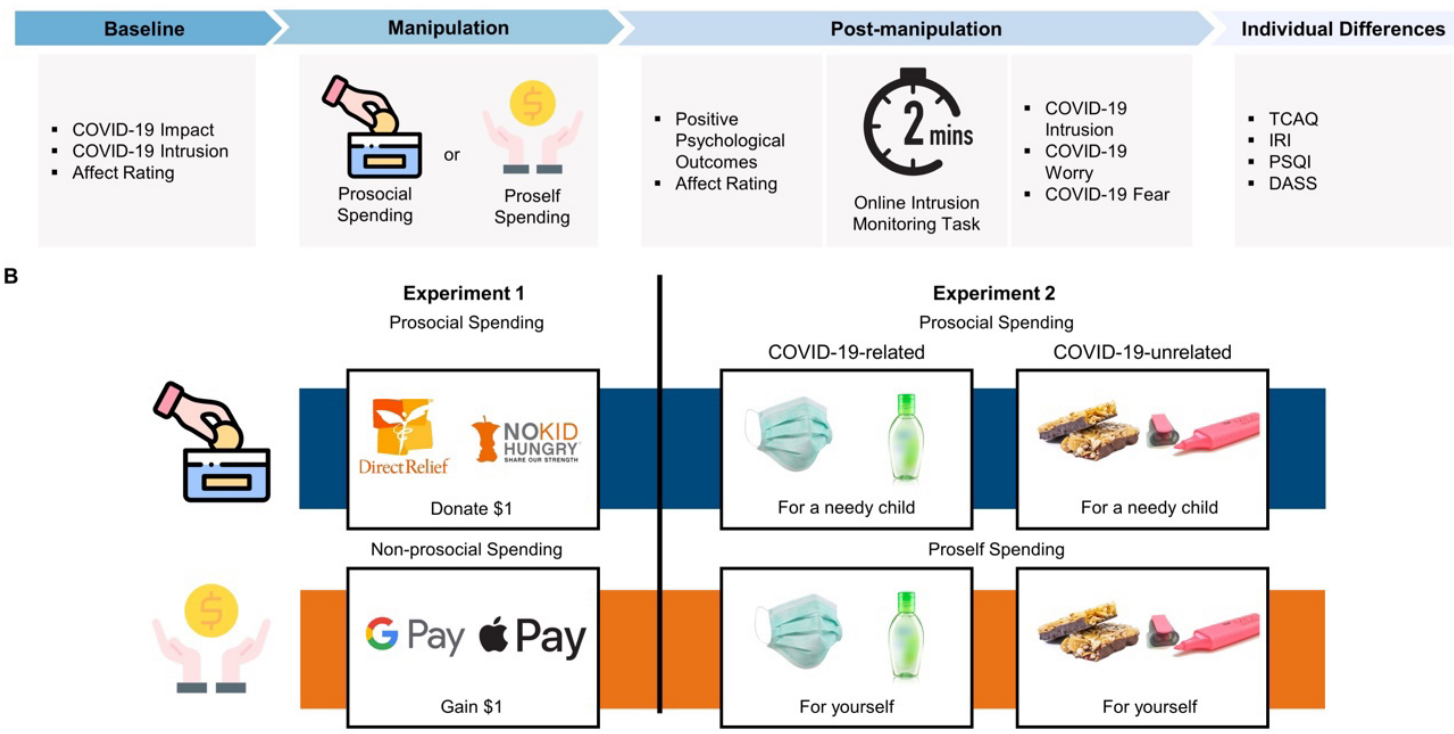

Figure 1. An overview of the experimental procedures in Experiments 1 and 2. A) Experiments 1 and 2 task flows and B) Prosocial vs. non-prosocial or proself manipulations in Experiments 1 and 2, respectively. In Experiment 2, COVID-relatedness was manipulated using both instructions and the purchased items: whether they were PPEs (masks and hand sanitizers, COVID-19-related) or general supplies that are not directly related to the COVID19 (snacks and writing supplies, COVID-19-unrelated).

Afterward, participants reported their current positive and negative affect (i.e., baseline affect) on a 7-point Likert scale (1: not at all to 7: extremely) for five positive items (inspired, relaxed, enthusiastic, happy, content) and five negative items (hopeless, fearful, anxious, depressed, sad). Cronbach's alphas for positive and negative affect measures were high at baseline and post-task assessments for both experiments $(0.85-0.92)$.

Following baseline affect ratings, participants were told that they had received a $5 \varnothing$ voucher that they could use in an upcoming task. Using an adapted version of the online goody bag paradigm from Hanniball and colleagues (2019), participants were randomly 
PROSOCIALITY PROMOTES WELL-BEING DURING COVID-19

assigned to either a prosocial or a non-prosocial control condition. In the prosocial condition, participants read about two US charities: Direct Relief, an organization that provides frontline health workers with medical resources (e.g., protective masks, exam gloves and isolation gowns) to protect them from COVID-19; and No Kid Hungry, an organization that provides free meals to children when schools are closed due to COVID-19. Participants could use their $5 \notin$ electronic voucher to donate $\$ 1$ dollar to their preferred charity. Given that autonomy is important for experiencing the emotional reward of prosocial decisions (Weinstein \& Ryan, 2010), participants were given the choice to opt-out of donating and keep the cash value ( $5 \varnothing$ US) for themselves (credited to their Prolific account). As in previous research (e.g., Aknin et al., 2013; Hanniball et al., 2019), we excluded participants who opted out of making a donation in the prosocial condition.

In the non-prosocial control condition, participants could choose to transfer the equivalent $\$ 1$ purchasing power of their $5 \varnothing$ electronic voucher to their digital wallet for personal use with either Google Pay, Apple Pay, or they could choose to receive the \$1 USD with their Prolific accounts. To equate the amount of information and choices presented in both conditions, participants in the non-prosocial control condition were given brief descriptions about the digital wallets. After making their financial decision, participants in both the prosocial and non-prosocial control conditions were asked to explain their selection by typing at least 150 characters into a blank text box; we added this novel step to the goody bag paradigm to increase the salience of one's recent prosocial or non-prosocial behavior.

Participants were then asked to complete a five-item questionnaire evaluating their recent actions (alpha $=0.88)$. Statements included: 1) I feel my act is meaningful; 2) My action will have a positive impact, 3) My action makes me feel empathetic for others' needs, (4) My action makes me feel I am social connected with others, and (5) I feel happy. Ratings were made on a 7-point Likert scale (1: not at all to 7: extremely). Participants then reported 
PROSOCIALITY PROMOTES WELL-BEING DURING COVID-19

their post-task positive and negative affect using the same items and scale from the baseline affect measure.

Afterward, participants completed a 2-minute COVID-19 thought intrusion monitoring task (adapted from Takarangi et al., 2014). Participants were instructed to click anywhere on the browser whenever they experienced a COVID-19-related intrusive thought. The total number of clicks provided an estimate of COVID-19 intrusive thoughts. To ensure participants did not leave their computer or navigate away from the survey, we asked participants to count the number of times that the letter " $A$ " appeared on the screen among three other letters $(\mathrm{L}, \mathrm{M}, \mathrm{Z})$ and respond after the intrusion monitoring task. This counting task also served as an attention check. With a correct response of 7, we pre-registered our intention to exclude participants who reported $<5$ or $>9$ from subsequent analyses.

Following the intrusion monitoring task, participants reported how frequently they thought about COVID-19 during the previous 2-minutes on a 4-item self-report questionnaire $($ alpha $=0.83)$, which was adapted from the Impact of Event Scale-revised intrusion subscale (Weiss \& Marmar, 1997). A sample item stated, “Thoughts related to COVID-19 suddenly or unexpectedly popped up in my mind", with participants answering on a 7-point Likert scale (1: not at all to 7: extremely). Participants next reported their worry (alpha $=0.94)$ and fear $($ alpha $=0.82)$ related to COVID-19 (adapted from Ahorsu et al., 2020; Freeman et al., 2020).

Finally, participants provided their demographic information and completed the Interpersonal Reactivity Index (IRI, Davis, 1980), Thought Control Ability Questionnaire (TCAQ, Luciano et al., 2005), Pittsburgh Sleep Quality Index (PSQI, Buysse et al., 1989) and Depression-Anxiety Stress Scale (DASS-21, Lovibond \& Lovibond, 1995).

Analysis Plan: Preregistered Analyses. We pre-registered our intention to compare conditions on post-task measures using parametric independent sample one-tailed $t$-tests or their non-parametric equivalent (one-tailed Mann-Whitney $U$ tests) if data violated normality 
PROSOCIALITY PROMOTES WELL-BEING DURING COVID-19

assumption in the Shapiro-Wilk normality test. When we measured both baseline and posttask scores, we pre-registered our intention to use Analyses of Covariance (ANCOVAs) to compare between-group differences on post-task outcomes, with baseline scores as covariates. We pre-registered our plans to exclude participants based on Prolific's bot/duplicate detection algorithm, attention check failures, etc $(n=75)$. While it was an oversight that we did not pre-register our plans to exclude participants based on their opt-out decisions, we excluded participants in the prosocial condition who did not engage in a prosocial act (i.e., "prosocial opt-outs", $n=35$ ) to be consistent with past research (Aknin et al., 2013, 2020; Hanniball et al., 2019). Individual differences between prosocial opt-in and opt-out participants are presented in Table S1. We included all participants in the nonprosocial condition, regardless of their choice, because everyone received \$ 1 USD. The final sample included 182 participants in the prosocial condition and 207 participants in the nonprosocial control condition.

Positive Psychological Outcomes. We examined each individual outcome rating and the overall average rating based on the 5 positive psychological outcome items.

Positive and Negative Affect. We calculated a mean positive and negative affect score for each participant at both baseline and post-task time points.

Intrusive thoughts. We calculated 1) the total number of COVID-19 related intrusive thoughts during the 2-minute monitoring task and 2) the standardized average score of selfreported intrusion frequencies during the monitoring task.

Subjective Worry/Fear about COVID-19: We computed an average rating of subjective worry and fear, separately, for each participant.

Individual Difference variables: Each construct was computed following its conventional scoring criterion. We examined whether these individual differences measures moderate the aforementioned results (see Supplemental Materials and Tables S6). 
PROSOCIALITY PROMOTES WELL-BEING DURING COVID-19

\section{Results}

Statistical analyses were performed using $R$ 4.0.0 and JASP 0.12.2. Sample sizes, descriptive statistics and 95\% CIs for each outcome measure are presented in Table 1. Cohen's $d s$ are calculated based on means and the standard deviations (SD) of the prosocial vs. non-prosocial control conditions. We report Bayes Factors $\left(\mathrm{BF}_{10}\right)$ to present the likelihood that observed data favour the alternative hypothesis over null hypothesis $\left(\mathrm{H}_{1} \mathrm{vs} . \mathrm{H}_{0}\right)$. Based on conventional criterion (Dienes, 2014), $\mathrm{BF}_{10}>3$ suggests conclusive evidence favouring the alternative hypothesis; $\mathrm{BF}_{10}<0.3$ suggests conclusive evidence favouring the null hypothesis; and $\mathrm{BF}_{10}$ between 0.3 and 3 suggests inconclusive evidence favouring either hypothesis. The following measures violated normality assumptions: average scores and individual ratings from positive psychological outcomes ( $p s<.001)$, total number of intrusions $(p<.001)$, subjective fear $(p<.001)$ and worry $(p=.005)$. Given that we did not find the prosocial vs. non-prosocial effects in intrusive thoughts nor subjective worry/fear, these results are reported in Supplemental Materials.

\section{Pre-registered Analyses:}

Positive psychological outcomes. Consistent with our pre-registered hypotheses, participants in prosocial condition reported higher levels of overall positive psychological functioning $(M=4.80, S D=1.23)$ than participants in the non-prosocial control condition $(M$ $=3.31, S D=1.32), W=7832, p<.001, d=1.16, \mathrm{BF}_{10}=2.30 \times 10^{23}$. Similarly, when looking at the individual items, participants in the prosocial condition also reported higher levels of meaningfulness $(d=0.73)$, positive impact $(d=0.90)$, empathy $(d=1.78)$, and social connectedness $\left(d=1.26 ; p \mathrm{~s}<.001, \mathrm{BF}_{10}>3.00 \times 10^{9}\right.$, Figure $\left.2 \mathrm{~A}\right)$ than participants in the non-prosocial control condition. However, prosocial behavior did not increase happiness on the single-item measure, $p=.343, d=0.06$, with $\mathrm{BF}_{10}=0.20$ showing that the data were 5 times (i.e., 1/0.20) more likely under the null than the alternative model, Table 1). 

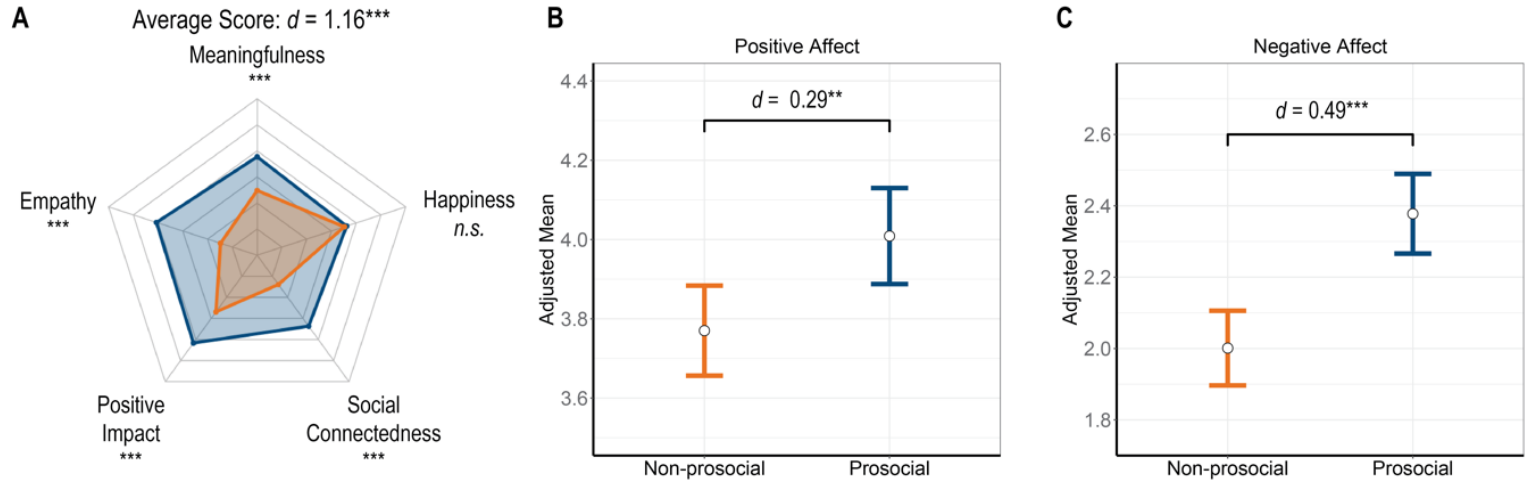

Figure 2. Results of Experiment 1. A: Participants in the prosocial condition reported higher levels of empathy, positive impact, social connectedness, and meaningfulness but not happiness than participants in the non-prosocial condition. B: Post-task positive affect adjusting baseline positive affect. C: Post-task negative affect adjusting baseline negative affect. ${ }^{* * *}: p<.001, * * p<.01 ;$ n.s.: $p>.05$.

Positive affect. Consistent with our pre-registered hypothesis, an ANCOVA controlling for baseline positive affect revealed that participants in the prosocial condition reported significantly higher levels of positive affect $(M=4.01, S D=0.83)$ after the task than participants in the non-prosocial control condition $(M=3.77, S D=0.83), F(1,386)=7.97, p$ $=.005, d=0.29$, with $\mathrm{BF}_{10}$ factor showing that the data were 4.77 more likely under the alternative as opposed to the null model(Table 1, Figure 2C)..

Negative affect. Counter to our pre-registered hypothesis, an ANCOVA controlling for baseline negative affect revealed that participants in the prosocial condition reported significantly higher levels of negative affect $(M=2.38, S D=0.77)$ than participants in the non-prosocial control condition after the task $(M=2.00, S D=0.77), F(1,386)=23.37, p$ $<.001, d=0.49$, with the $\mathrm{BF}_{10}$ factor showing that the data were 6999 more likely under the alternative as opposed to the null model (Table 1, Figure 2D).

Exploratory analyses controlling individual differences $(N=389)$. Participants in the prosocial condition reported significantly higher scores on our measure of baseline alertness (SSS), depression, anxiety (DASS-21) and thought control (TCAQ) than 
PROSOCIALITY PROMOTES WELL-BEING DURING COVID-19

participants in the non-prosocial control condition (see Table S4). Given that these

differences could influence post-task affect, we conducted linear regression analyses in which we predicted post-task positive and negative affect using 1) conditions, 2) baseline affect, and 2) all individual difference variables. Results confirmed that conditions remained a significant predictor for post-task positive and negative affect ( $p$ s $<.02$, see Table S5) while controlling for baseline affect and individual differences. 
Table 1. Experiment 1 means, SD, 95\% CIs, and Cohen's $d$ effect size estimates for pre-registered outcome comparisons, based on $N=389$. Bonferroni corrected $p$-values were reported $* * p<.01, * * * p<.001$.

\begin{tabular}{|c|c|c|c|c|}
\hline Outcome measurements & Prosocial $(n=182)$ & Non-Prosocial $(n=207)$ & $d$ & $p_{\text {corr }}$ \\
\hline Positive Outcomes (5-item avg.) & $4.80(1.23)[4.64,5.01]$ & $3.31(1.32)[3.14,3.50]$ & 1.16 & $<0.001$ \\
\hline Happiness & $4.62(1.47)[4.41,4.85]$ & $4.52(1.54)[4.29,4.71]$ & 0.06 & 1.000 \\
\hline Meaningfulness & $4.77(1.56)[4.54,5.01]$ & $3.48(1.95)[3.22,3.75]$ & 0.73 & $<0.001$ \\
\hline Positive Impact & $5.16(1.38)[4.97,5.37]$ & $3.69(1.83)[3.41,3.94]$ & 0.90 & $<0.001$ \\
\hline Empathy & $5.07(1.26)[4.89,5.27]$ & $2.48(1.61)[2.27,2.72]$ & 1.78 & $<0.001$ \\
\hline Social Connectedness & $4.37(1.59)[4.15,4.63]$ & $2.39(1.54)[2.16,2.59]$ & 1.26 & $<0.001$ \\
\hline Positive Affect (adjusted mean) & $4.01(0.83)[3.89,4.13]$ & $3.77(0.83)[3.67,3.88]$ & 0.29 & 0.060 \\
\hline Negative Affect (adjusted mean) & $2.38(0.77)[2.27,2.49]$ & $2.00(0.77)[1.90,2.11]$ & 0.49 & $<0.001$ \\
\hline COVID-19 Intrusion Frequency & $2.47(3.08)[2.06,2.95]$ & $2.23(2.83)[1.88,2.63]$ & 0.08 & 1.000 \\
\hline Self-reported COVID-19 Intrusions & $2.43(1.21)[2.26,2.62]$ & $2.29(1.22)[2.13,2.45]$ & 0.12 & 1.000 \\
\hline COVID-19 Worry & $1.68(0.94)[1.53,1.82]$ & $1.56(1.07)[1.42,1.71]$ & 0.12 & 1.000 \\
\hline COVID-19 Fear & $0.87(0.72)[0.77,0.99]$ & $0.81(0.74)[0.72,0.91]$ & 0.09 & 1.000 \\
\hline
\end{tabular}

Note: Cohen's $d s$ were calculated using means and SDs from the two conditions $(d>0$ : prosocial $>$ non-prosocial). Intrusion frequency refers to number of COVID-19 thought intrusions captured during the 2-minute intrusion monitoring task; self-reported intrusions refer to post-task selfreported intrusions. 
PROSOCIALITY PROMOTES WELL-BEING DURING COVID-19

\section{Discussion}

Consistent with our pre-registered hypotheses, spending $5 \notin$ US to make a \$1 USD donation led to higher levels of positive affect and positive psychological outcomes (except for the 1-item measure of happiness) than personally receiving \$1 USD. However, counter to our pre-registered hypotheses, engaging in a prosocial vs. non-prosocial choice did not influence negative psychological outcomes such as intrusive thoughts, subjective worry or fear related to COVID-19. Moreover, while negative affect reduced from baseline to posttask assessments across the entire sample, participants in the prosocial condition reported significantly higher levels of negative affect than participants in the non-prosocial control condition. Smaller decreases in negative affect observed among participants in the prosocial condition could have occurred because participants in the prosocial condition were repeatedly reminded about COVID-19, while participants in the non-prosocial condition had their attention temporarily diverted away from COVID-19 during the task. Indeed, reference to the pandemic in the prosocial task may have reminded participants of the suffering the pandemic had caused (e.g., frontline health workers who lack protection gear), contributing to higher negative affect. While this explanation is post-hoc and speculative, it aligns with existing evidence documenting a robust association between COVID-19 information exposure and lower well-being and greater distress (e.g., Bu et al., 2020; Gao et al., 2020; Huckins et al., 2020).

One critical limitation is that participants in the prosocial and non-prosocial conditions received "opt-out" choices with different features, which may have also resulted in different perception of autonomy across conditions. Specifically, participants in the prosocial condition decided whether to donate \$1 USD to one of two charities or to opt-out, meaning that they would receive $5 \notin$. Meanwhile, participants in the non-prosocial condition decided how they would receive \$ 1 USD depending on their choices of platforms (google, apple or 
PROSOCIALITY PROMOTES WELL-BEING DURING COVID-19

prolific). Accordingly, participants in the prosocial condition may have experienced higher levels of autonomy than participants in the non-prosocial condition, which may have influenced results. We addressed this limitation in Experiment 2 wherein participants were offered the choice to opt-in vs. opt-out from engaging in a prosocial vs. proself act with equivalent outcomes (see Experiment 2 Methods for details).

Despite the aforesaid limitation, the results of Experiment 1 raise several intriguing questions. First, does prosocial behavior need to be directly related to the source of stress/anxiety (e.g., COVID-19) to have emotional benefits? Second, does reading COVID19-related information alone increase negative affect in the context of an on-going global pandemic? To address these questions, we directly manipulated whether purchasing items were related to COVID-19 in a 2 (prosocial vs. proself) X 2 (COVID-19-related vs. COVID19-unrelated) between-subjects design (Figure 1B). In the COVID-19-related conditions, participants could purchase either a face mask or hand sanitizer, and they read how these PPEs could be important for health during the COVID-19 pandemic. In the COVID-19unrelated conditions, participants could purchase either healthy snacks or writing supplies, and they read how snacks/writing supplies could be important for nutrition/academic performance without COVID-19-related information. We also manipulated whether these items were available for purchase for oneself (in the proself condition) or for a needy child (in the prosocial condition). This 2 X 2 design allowed us to not only examine our preregistered hypothesis examining whether prosocial behavior enhances positive affect during the pandemic, but it also allowed us to examine the main effects of COVID-19-relatedness on participants' emotional responses, as well as their interactions. To our knowledge, this is the first investigation of how prosocial behavior's relatedness to the source of stress (COVID-19 in the present context) may influence its emotional benefits. 


\section{Experiment 2}

\section{Methods}

Participants. An a priori power analysis $(\beta=80 \%, \alpha=5 \%)$ revealed that we required 1,200 participants to detect a relatively small effect size (Cohen's $d=0.23$ ) in a 2 (prosocial vs. proself) X 2 (COVID-19-related vs. COVID-19-unrelated) between-subjects design. Anticipating an exclusion rate of approximately 20-25\% (based on Experiment 1, see also Pennycook et al., 2020), we collected data from 1,421 participants who submitted responses on Prolific Academic (668 female, age: $M=26.34$ years old, $S D=6.32$ ). Participants were randomly assigned to one of the four conditions in our between-subjects design. Data collection began on April 24 and ended on April 30, 2020 when we reached our target sample size.

Materials and Procedure. The procedure was the same as Experiment 1, except 1) we added a self-report measure of perceived competence to the positive psychological outcomes (alpha $=0.91) ; 2$ ) we changed prosocial and proself tasks into a 2 by 2 design (Figure 1); and 3) we removed the 150-character writing task.

\section{Prosocial vs. Proself tasks in COVID-19-related vs. COVID-19-unrelated}

conditions. After completing the baseline survey, participants read that they had received an additional payment of $5 \phi$ US in the form of an electronic voucher with a purchasing power of \$1 USD. Participants in the prosocial conditions could use the \$1 USD to purchase an item for a needy child from a low-income American family through real, online donation campaigns posted on DonorsChoose.org. Meanwhile, participants in the proself conditions could use the \$1 USD to purchase equivalent items for themselves. In the COVID-19-related conditions, participants could purchase personal protection equipment (PPE), such as a reusable face mask or hand sanitizer - two essential hygiene items during the pandemic. In 
PROSOCIALITY PROMOTES WELL-BEING DURING COVID-19

the COVID-19-unrelated condition, participants could purchase healthy snacks or writing supplies - items that were not directly related to COVID-19.

Participants then read information about the importance of the items available. Specifically, in the prosocial/COVID-19-related condition, participants were told how PPEs and sanitizer are important in protecting the needy child's health during the pandemic. In the prosocial/COVID-19-unrelated condition, participants read how snacks/writing supplies were important for the needy child's nutrition/academic performance, and they did not read any COVID-19-related information. In the proself conditions, participants were presented with similar information but beneficiary of each purchase was themselves (see OSF for materials).

Similar to Hanniball and colleagues (2019), participants could opt-out from making a purchasing choice in all four conditions and keep the cash value (5ф US) for themselves (credited to their Prolific account). The opportunity to opt-out of making a purchase was provided to encourage a sense of volition, which past research shown to be critical for experiencing the emotional rewards of prosocial behavior (Weinstein \& Ryan, 2010). The higher monetary value gained by making a \$1 USD purchase over claiming 5 cents was intentionally used here to encourage participants to engage in similar purchasing behavior across conditions (see Hanniball et al., 2019 for similar study design). To further discourage opt-outs, participants were informed that the $5 \notin$ US would be credited to their Prolific account at a later date in $\sim 3$ months.

Participants were informed that the goods they purchased would be delivered to them after the study. At the end of the study, however, to avoid collecting personal data (e.g., mailing address) required for delivery, opt-in participants in the proself conditions were later informed that they would receive the value (\$1 USD) credited to their Prolific account (for verbatim instruction, see https://osf.io/bx5ge/). 
PROSOCIALITY PROMOTES WELL-BEING DURING COVID-19

Pre-registered Analyses. Analyses were same as in Experiment 1, except that $t$ tests/Mann-Whitney $U$ tests /ANCOVAs were run on prosocial vs. proself comparisons within COVID-19-related and COVID-19-unrelated conditions, separately.

We pre-registered our plan to explore whether COVID-relatedness moderated the emotional benefits of prosocial behavior with a series of 2 (COVID-19-related vs. COVID19-unrelated) X 2 (prosocial vs. proself) ANOVAs on positive psychological outcomes, intrusive thoughts frequency from intrusion monitoring task, and on subjective worry/fear. For positive/negative affect, and self-report COVID-19 intrusive thoughts, we conducted mixed 2 (time, baseline vs. post-task, within-subjects) X 2 (COVID-19-related vs. COVID19-unrelated, between-subjects) X 2 (prosocial vs. proself, between-subjects) ANOVAs.

We pre-registered our intention to analyze the data excluding prosocial opt-out participants. We also pre-registered our intentions to present results twice: (a) with proself opt-outs included, and (b) with proself opt-outs excluded. Participants who opted out in the proself condition still made a self-gain (i.e., receiving $5 \varnothing \mathrm{US}$ ), justifying their inclusion (see also Aknin et al., 2020; Hanniball et al., 2019). On the other hand, excluding proself opt-out participants makes the prosocial vs. proself condition more comparable because all remaining participants complied with instructions (i.e., chose to opt-in) and selected an item with an identical cash value (i.e., \$1 USD). Detailed exclusions, sample sizes and statistical power are presented in Table 2 .

Opt-out rates were not significantly different between COVID-19-related and COVID-19unrelated prosocial conditions $\left(X^{2}(1)=0.28, p=.60\right)$. However, we did find meaningful differences between opt-out and opt-in participants. In the prosocial conditions, opt-out participants reported lower scores of empathetic concerns than opt-in participants in both COVID-19-related and -unrelated conditions $(p s<.01)$. Across prosocial and proself conditions, opt-out participants reported that they were less impacted by the COVID-19, 
PROSOCIALITY PROMOTES WELL-BEING DURING COVID-19

which may explain why they chose to disengage from the prosocial or proself behavior (see Table S2-3 for details). Note that these individual differences did not moderate emotional benefits of prosocial behavior (see Supplementary Materials). 
PROSOCIALITY PROMOTES WELL-BEING DURING COVID-19

Table 2. Sample size and exclusion information for Experiment 2.

\begin{tabular}{|c|c|c|c|c|c|c|c|c|c|}
\hline & \multirow{2}{*}{$\begin{array}{c}\text { Entire } \\
\text { Sample }\end{array}$} & \multirow[t]{2}{*}{ Excluded $^{1}$} & \multicolumn{3}{|c|}{ Prosocial } & \multicolumn{3}{|c|}{ Proself } & \multirow{2}{*}{$\begin{array}{c}\text { Statistical } \\
\text { power }^{3}\end{array}$} \\
\hline & & & $\begin{array}{c}\text { Entire } \\
\text { prosocial } \\
\text { sample }\end{array}$ & $\begin{array}{c}\text { Prosocial } \\
\text { opt-outs } \\
\left(\text { Excluded }^{2}\right)\end{array}$ & $\begin{array}{c}\text { Prosocial } \\
\text { opt-ins }\end{array}$ & $\begin{array}{l}\text { Entire } \\
\text { proself } \\
\text { sample }\end{array}$ & $\begin{array}{c}\text { Proself } \\
\text { opt-outs }\end{array}$ & $\begin{array}{l}\text { Proself } \\
\text { opt-ins }\end{array}$ & \\
\hline Experiment 2 & 1421 & 105 & 652 & 82 & 570 & 664 & 278 & 386 & \\
\hline COVID-19-Related & 706 & 47 & 330 & 48 & 282 & 329 & 128 & 201 & $0.81,0.70$ \\
\hline COVID-19-Unrelated & 715 & 58 & 322 & 34 & 288 & 335 & 150 & 185 & $0.82,0.68$ \\
\hline
\end{tabular}

Note: ${ }^{1}$ Pre-registered exclusion criteria, including bot/duplicate detection and attention check failure. ${ }^{2}$ We pre-registered our intention to exclude participants who chose to opt-out in the prosocial conditions because they did not perform a prosocial act (consistent with Aknin et al., 2013; 2020; Hanniball et al 2019). The prosocial opt-out rate observed in Experiment 2 was $6.2 \%$ (82 out of 1316), which was comparable to data collected using a similar online prosocial spending paradigm before the COVID-19 pandemic (8.4\% prosocial opt-out rate, see Hanniball et al., 2019 Table 1). ${ }^{3}$ Statistical power indicates the achieved power in detecting pre-registered effect sizes (Cohen's $d=0.23$ in Experiment 2 , false positive rate $=5 \%$ ) when sample includes prosocial opt-in participants and entire proself sample (left), and when sample includes prosocial opt-in participants and proself opt-in participants (right in italics). 
PROSOCIALITY PROMOTES WELL-BEING DURING COVID-19

\section{Results}

Means, standard deviations, 95\% CIs, and Cohen's $d$ s are presented in Tables 3 and 4 for the COVID-19-related and COVID-19-unrelated conditions, respectively. The following measures violated normality assumptions: averaged and individual ratings from positive psychological outcomes $(p s<.001)$, intrusions $(p<.001)$, subjective fear $(p<.001)$ and worry $(p<.004)$. Given that we did not find any effects on intrusive thoughts nor subjective worry/fear, these results are reported in Supplemental Materials.

Pre-registered Confirmatory Analyses: Including proself opt-out participants $N=1,234$

Positive psychological outcomes. Consistent with our pre-registered hypotheses, participants in the prosocial (vs. proself) condition reported higher positive psychological outcomes in both the COVID-19-related (prosocial, $M=4.78, S D=1.23$; proself, $M=3.95$, $S D=1.43$ ) and COVID-19-unrelated conditions (prosocial, $M=4.92, S D=1.31 ;$ proself, $M$ $=3.35, S D=1.28, d \mathrm{~s}>0.60, p s<.001, \mathrm{BF}_{10}>1 \times 10^{11}$ ), with $\mathrm{BF}_{10}$ strongly favouring the alternative hypothesis. Specifically, in the COVID-19-related conditions, prosocial behavior led to greater feelings of happiness, meaningfulness, positive impact, empathy, social connectedness $\left(d s: 0.32-0.87, p s<.001 \mathrm{BFs}_{10}>300\right)$, but not competence $(p=.377, d=0.04$, $\mathrm{BF}_{10}=0.14$, Figure 3A, Table 3). In the COVID-19-unrelated condition, prosocial (vs. proself) spending led to elevated reports on all positive outcomes, $d \mathrm{~s}: 0.38-1.91, p s<.001$, with $\mathrm{BF}_{10}$ factor showing that the data were 9000 times more likely under the alternative as opposed to the null model (see Figure 3C, Table 4). 


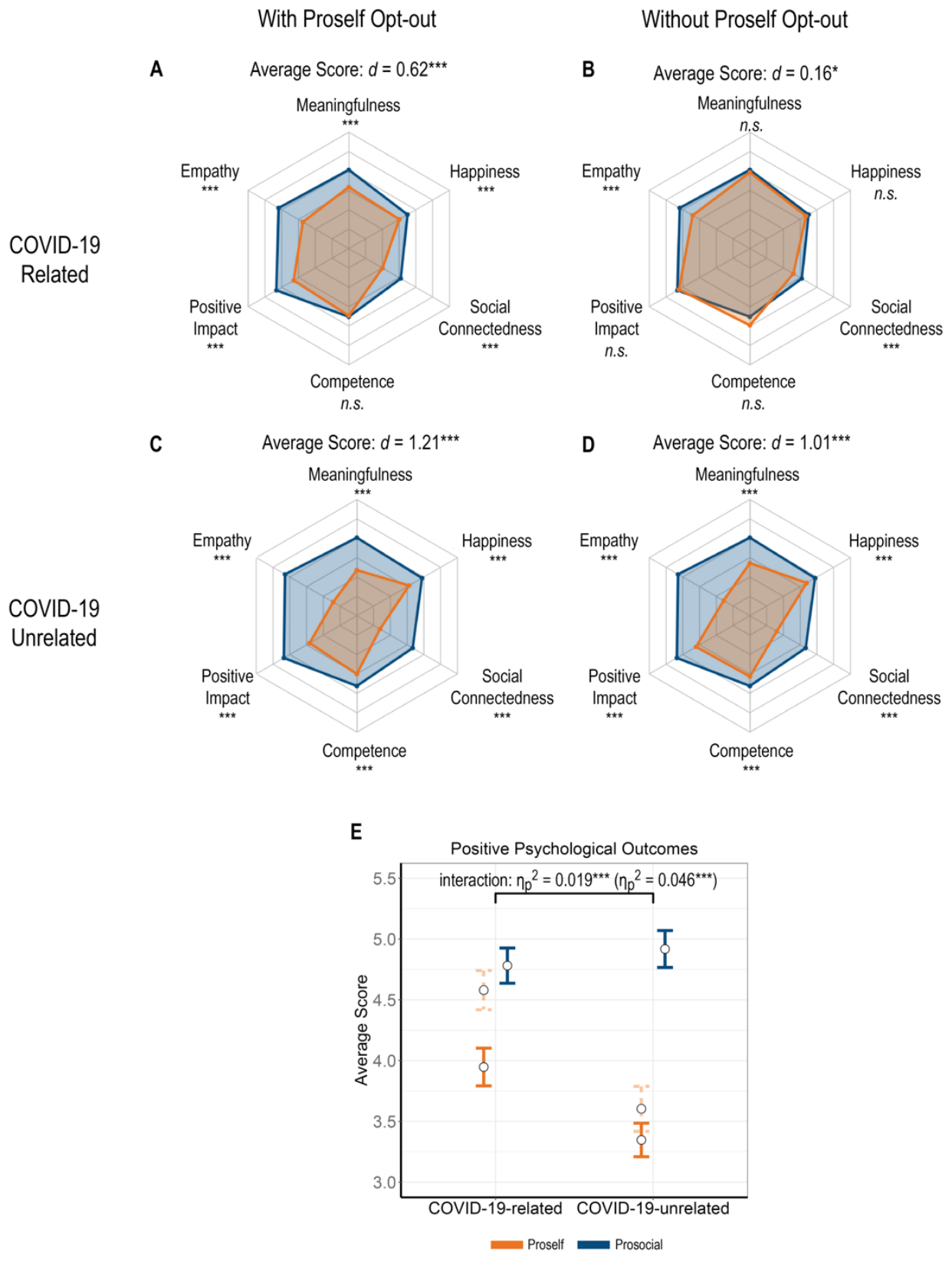

Figure 3. Positive psychological outcome ratings from the COVID-19-related and COVID19-unrelated conditions in Experiment 2. Results were calculated with proself opt-out participants (Panels A and C) and without proself opt-outs (Panels B and D). Panel E depicts the COVID-19-relatedness by prosocial vs. proself interaction. While prosocial (vs. proself) behavior led to higher positive psychological outcomes in both conditions, the benefits were significantly larger in the COVID-19-unrelated conditions. ${ }^{* * *}: p<.001$, Error bars indicate $95 \%$ CIs. Dashed lines present the results without proself opt-out participants.

Positive affect. Consistent with our pre-registered hypotheses, ANCOVAs controlling for baseline positive affect revealed that participants in the prosocial condition reported higher post-task positive affect than participants in the proself condition, in both the COVID- 
19-related condition (prosocial, $M=3.92, S D=0.84$; proself, $M=3.63, S D=0.84, F(1,608)$

$=18.63, p<.001, d=0.35, \mathrm{BF}_{10}=713.88$, Figure 4A, Table 3$)$ and COVID-19-unrelated condition (prosocial, $M=4.13, S D=0.90$; proself, $M=3.71, S D=0.90, F(1,620)=34.29, p$ $<.001, d=0.47, \mathrm{BF}_{10}=1.05 \times 10^{6}$, Figure 4A, Table 4). Both $\mathrm{BF}_{10}$ factors strongly support the alternative as opposed to the null model.
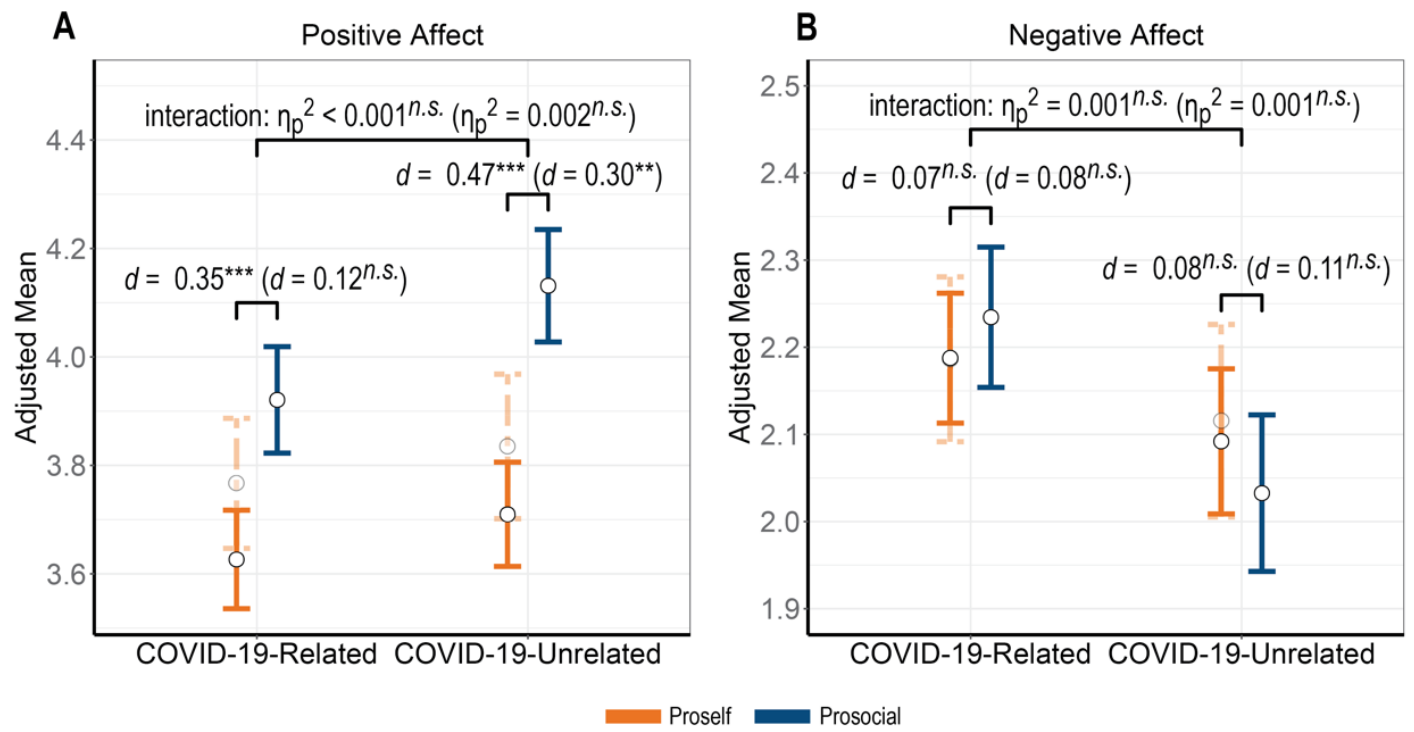

Figure 4. Results of Experiment 2 on post-task positive and negative affect, adjusting baseline affect measures. A: post-task positive affect and B: post-task negative affect reported by participants in the prosocial and proself conditions in COVID-19-related, and COVID-19unrelated condition. Error bars indicate 95\% confidential intervals. Dashed lines and Cohen's $d \mathrm{~s}$ in parentheses indicate results excluding proself opt-out participants. ${ }^{* * *}: p<.001, * *: p$ $<.01$, n.s.: $p>.05$.

Negative affect. Counter to our pre-registered hypotheses, ANCOVAs controlling for baseline negative affect revealed that post-spending negative affect did not significantly differ between prosocial and proself acts in the COVID-19-related conditions $(F(1,608)=$ $0.71, p=.401, \eta_{\mathrm{p}}{ }^{2}=0.001, d=0.07, \mathrm{BF}_{10}=0.12 ;$ nor the COVID-19-unrelated conditions, $F$ $(1,620)=0.91, p=.341, \eta_{\mathrm{p}}{ }^{2}=0.001, d=0.08, \mathrm{BF}_{10}=0.12$, see Figure. 4B, Tables 3, 4). with $\mathrm{BF}_{10}$ showing that the data were about 8.3 times (i.e., 1/0.12) more likely under the null than the alternative model.

Pre-registered Exploratory Analyses: Including proself opt-out participants, $N=1,234$ 
PROSOCIALITY PROMOTES WELL-BEING DURING COVID-19

Positive psychological outcomes. An ANOVA on average positive psychological outcomes revealed a significant Condition by COVID-19-relatedness interaction: $F(1,1230)=$ 23.90, $p<.001, \eta_{\mathrm{p}}{ }^{2}=0.019$, with $\mathrm{BF}_{10}$ showing the data were 9610 times more likely under the alternative as opposed to the null model (see Figure 3C). Post-hoc Bonferroni-corrected comparisons showed that the prosocial vs. proself psychological benefits in the COVID-19unrelated condition $(t(1230)=14.81, p<.001, d=1.21)$ were nearly twice as large as those in the COVID-19-related condition $(t(1230)=7.79, p<.001, d=0.62)$.

Positive affect. A mixed ANOVA revealed that the three-way Time by COVID-19relatedness by Condition interaction was not significant $F(1,1230)=0.87, p=.351, \eta_{\mathrm{p}}{ }^{2}$ $<.001$, with $\mathrm{BF}_{10}=0.38$ providing inconclusive evidence supporting the alternative model, i.e., the data were 2.63 times $(1 / 0.38)$ more likely under the null than the alternative model. Thus, COVID-19-relatedness did not moderate prosocial behavior's enhancements of positive affect (Figure 4A). However, we found a significant COVID-19-relatedness by Time interaction, $F(1,1230)=9.67, p=.002, \eta_{\mathrm{p}}{ }^{2}=.008$. To break down this interaction, we calculated positive affect change scores (Time 2-Time 1 positive affect, with higher scores indicating elevated positive affect from baseline to post-task). We found that participants in the COVID-19-unrelated conditions reported higher positive affect enhancements than participants in the COVID-19-related conditions, $W=173236, p=.006, d=0.17$, with $\mathrm{BF}_{10}$ showing that the data were 5.26 times more likely under the alternative as opposed to the null model.

Negative affect. The same three-way interaction on negative affect was not significant $F(1,1230)=0.87, p=.350, \eta_{\mathrm{p}}^{2}=.001$, with the $\mathrm{BF}_{10}=0.14$ providing conclusive evidence favouring the null model. Again, we found a significant COVID-19-relatedness by time interaction, $F(1,1230)=14.68, p<.001, \eta_{\mathrm{p}}{ }^{2}=.012$, with $\mathrm{BF}_{10}$ showing that the data were 69.38 times more likely under the alternative as opposed to the null model. To break down 
PROSOCIALITY PROMOTES WELL-BEING DURING COVID-19

this interaction, we calculated negative affect change scores (Time 2-Time 1 negative affect,

with negative scores indicating reduced negative affect from baseline to post-task). We found that COVID-19-unrelated participants showed larger negative affect reduction than COVID19-related participants, $W=210498, p=.001, d=0.21$, with $\mathrm{BF}_{10}$ showing that the data were 69.59 times more likely under the alternative as opposed to the null model (Figure 4B).

Pre-registered Confirmatory Analyses: Excluding proself opt-out participants, $N=957$

Positive psychological outcomes. Consistent with our pre-registered predictions, in the COVID-19-related conditions, participants in the prosocial (vs. proself) condition reported higher average positive psychological outcomes, with $\mathrm{BF}_{10}$ providing inconclusive evidence favouring the null model (prosocial, $M=4.78, S D=1.23$; proself, $M=4.58, S D=$ $\left.1.16, W=25274, p=.017, d=0.17, \mathrm{BF}_{10}=0.98\right)$. Participants in the prosocial (vs. proself) condition also reported higher scores on empathy and social connectedness $(d \mathrm{~s}>0.30, p \mathrm{~s}$ $<.001)$, but not on happiness, meaningfulness, positive impact nor competence $(d s=-0.30-$ 0.09 , ps $>.070, \mathrm{BFs}_{10}<0.35$, see Figure 3B, Table 3).

In the COVID-19-unrelated conditions, participants in the prosocial (vs. proself) condition reported significantly higher average positive psychological outcomes, with $\mathrm{BF}_{10}$ providing conclusive evidence favouring the alternative hypothesis (prosocial, $M=4.92, S D$ $=1.31$; proself, $M=3.60, S D=1.28, W=12268, p<.001, d=1.01, \mathrm{BF}_{10}=2.34 \times 10^{21}$ ), as well as higher scores on all six individual items $\left(p \mathrm{~s}<.001, d \mathrm{~s}>0.30, \mathrm{BF}_{10}>30\right.$, Figure 3D, Table 4).

Positive affect. In contrast to our pre-registered predictions, the ANCOVA controlling for baseline positive affect did not detect a significant difference in post-task positive affect between prosocial and proself spending in the COVID-19-related conditions (prosocial, $M=$ 3.92, $S D=0.84$; proself, $M=3.77, S D=0.87, F(1,481)=1.91, p=.161, d=0.13$, 
$\mathrm{BF}_{10}=0.26$, indicating that the data were 3.85 times (i.e., 1/0.26) more likely under the null model as opposed to the alternative model (Table 3).

In the COVID-19-unrelated conditions, the same ANCOVA showed that prosocial participants reported higher post-task positive affect compared to proself participants, (prosocial, $M=4.92, S D=1.31$; proself, $M=3.60, S D=1.28, F(1,470)=10.92, p=.001, d$ $=0.30$, with $\mathrm{BF}_{10}$ showing that the data were 20 times more likely under the alternative as opposed to the null model (Figure 4A, Table 4).

Negative affect. In contrast to our pre-registered predictions, the ANCOVA on posttask negative affect showed there were no significant differences between proself and prosocial spending in the COVID-19-related conditions, $F(1,481)=0.82, p=.366, d=0.08$, $\mathrm{BF}_{10}=0.14$, nor in the COVID-19-unrelated conditions: $F(1,470)=1.31, p=.253, d=0.11$, $\mathrm{BF}_{10}=0.20$, see Figure 4B. $\mathrm{BFs}_{10}$ indicate that the data were 7.14 (i.e., 1/0.14) and 5 (i.e., 1/0.20) times more likely under the null as opposed to the alternative model.

\section{Pre-registered Exploratory Analyses: Excluding proself opt-out participants, $N=957$}

Positive psychological outcomes. The ANOVA on average positive psychological outcomes revealed a significant Condition by COVID-19-relatedness interaction, $F(1,953)=$ $45.50, p<.001, \eta_{\mathrm{p}}{ }^{2}=.046$, with $\mathrm{BF}_{10}$ providing conclusive evidence favouring the alternative hypothesis: $\mathrm{BF}_{10}=2.64 \times 10^{8}$. Bonferroni-corrected comparisons showed that the prosocial (vs. proself) behavior significantly enhanced positive psychological outcomes in the COVID19 -unrelated condition $\left(t(953)=11.15, p<.001, d=1.01, \mathrm{BF}_{10}=1.17 \times 10^{21}\right)$, while the prosocial vs. proself condition difference was not significant in the COVID-19-related condition $\left(t(953)=1.75, p=.479, d=0.17, \mathrm{BF}_{10}=0.51\right)$.

Moreover, among proself participants, purchasing PPEs (i.e., COVID-19-related) increased positive psychological outcomes more than purchasing food/writing supplies (i.e., COVID-19-unrelated): $t(953)=7.67, p<.001, d=0.80$, with $\mathrm{BF}_{10}$ showing that the data 
PROSOCIALITY PROMOTES WELL-BEING DURING COVID-19

were $1.62 \times 10^{11}$ times more likely under the alternative as opposed to the null model, see Figure 3E.

Positive affect. The time by COVID-19-relatedness by condition three-way interaction on positive affect was not significant, $F(1,953)=1.45, p=.228, \eta_{\mathrm{p}}{ }^{2}=.002$, with $\mathrm{BF}_{10}=0.19$, suggesting the data were 5.26 times (i.e., 1/0.19) more likely under the null as opposed to the alternative model. In line with the main findings, we found a significant COVID-19-relatedness by time interaction, $F(1,953)=4.79, p=.029, \eta_{\mathrm{p}}^{2}=.005, \mathrm{BF}_{10}=$ 13.76. Again, participants in the COVID-19-unrelated conditions reported higher positive affect increases (from baseline to post-task) than participants in the COVID-19-related conditions, $W=104525, p=.020, d=0.16, \mathrm{BF}_{10}=1.27$, indicating that the data were 1.27 times more likely under the alternative model as opposed to the null model.

Negative affect. The time by COVID-19-relatedness by condition three-way interaction on negative affect was not significant, $F(1,953)=1.23, p=.268, \eta_{\mathrm{p}}{ }^{2}=.001, \mathrm{BF}_{10}$ $=0.19$, suggesting the data were 5.26 (i.e., 1/0.19) times more likely under the null as opposed to the alternative model. Again, we found a significant COVID-19-relatedness by time interaction, $F(1,953)=9.17, p=.003, \eta_{\mathrm{p}}^{2}=.01$ : participants in the COVID-19unrelated conditions showed larger negative affect reduction than participants in the COVID19-related conditions, $W=125871, p=.007, d=0.21$, with $\mathrm{BF}_{10}$ showing that the data were 14.87 times more likely under the alternative as opposed to the null model.

\section{Impact of excluding proself opt-out participants in Experiment 2}

While participants in the proself condition who decided to make a purchase received PPEs and food/writing supplies worth $\$ 1$ USD, participants in the proself condition who opted-out received a smaller and delayed reward of $5 \phi$ US. Thus, excluding proself opt-out participants who were presumably less pleased with their choice increased average ratings on the positive psychological outcome measure and post-task positive affect, thereby minimizing 
PROSOCIALITY PROMOTES WELL-BEING DURING COVID-19

differences between the prosocial vs. proself conditions (Figure 3E, Figure 4A, Tables 3-4). The reduced emotional benefit of prosocial (vs. proself) behavior was most evident in the COVID-19-related condition where the effect size dropped from 0.62 to 0.16 on positive psychological outcomes, and from 0.35 to 0.12 on post-task positive affect. Meanwhile, in the COVID-19-unrelated condition, prosocial behavior's emotional benefits remained significant regardless of inclusion of exclusion of proself opt-out participants. Inspecting Figure 4A also suggests that among prosocial participants, donating PPEs were associated with lower positive affect $(M=4.13, S D=0.90)$ than donating food/writing supplies $(M=$ 3.92, $S D=0.84, W=36462, p=.035, d=0.23$ ), which further contributed to the smaller effect sizes of prosocial behavior's benefits observed in the COVID-19-related conditions.

To summarize, we found relatively robust support for the emotional benefits of prosocial behavior during COVID-19. The well-being benefits were most pronounced and reliable in the COVID-19-unrelated conditions, where prosocial behavior consistently increased positive affect and positive psychological outcomes (except for competence), regardless of whether analyses included participants who chose to opt-out of spending on themselves or not. Meanwhile, results were less reliable in the COVID-19-related conditions: when including only opt-in participants from prosocial and proself conditions, prosocial (vs. proself) behavior led to greater overall positive psychological outcomes including empathy and social connectedness, but not happiness, positive impact, meaningfulness, post-task positive affect. Heterogenous effects should be interpreted with caution because several constructs (e.g. competence, meaningfulness) were captured using single-item measures. It is possible that results may differ if longer and more reliable measurement instruments are used in future research. 
PROSOCIALITY PROMOTES WELL-BEING DURING COVID-19

Table 3. Experiment 2, COVID-19-Related conditions. Means, SDs, 95\% CIs, and Cohen's $d$ estimates for pre-registered outcome comparisons. Bonferroni corrected $p$-values were reported $* p<.05, * * p<.01, * * * p<.001$.

\begin{tabular}{|c|c|c|c|c|c|c|c|}
\hline \multirow[t]{2}{*}{ Outcome measurements } & \multirow[t]{2}{*}{ Prosocial $(n=282)$} & \multicolumn{3}{|c|}{ Including Proself Opt-out } & \multicolumn{3}{|c|}{ Excluding Proself Opt-out } \\
\hline & & Proself $(n=329)$ & $d$ & $p_{\text {corr }}$ & Proself $(n=202)$ & $d$ & $p_{\text {corr }}$ \\
\hline Positive Outcomes & $4.78(1.23)[4.64,4.92]$ & $3.95(1.43)[3.80,4.11]$ & 0.62 & $<.001$ & $4.58(1.16)[4.43,4.73]$ & 0.17 & .223 \\
\hline Happiness & $4.50(1.52)[4.31,4.67]$ & $4.01(1.56)[3.83,4.18]$ & 0.32 & $<.001$ & $4.35(1.45)[4.16,4.53]$ & 0.10 & .905 \\
\hline Meaningfulness & $5.06(1.47)[4.89,5.22]$ & $4.17(1.87)[3.98,4.36]$ & 0.52 & $<.001$ & $4.93(1.41)[4.73,5.10]$ & 0.09 & 1.000 \\
\hline Positive Impact & $5.32(1.36)[5.16,5.48]$ & $4.29(1.88)[4.09,4.48]$ & 0.62 & $<.001$ & $5.23(1.27)[5.05,5.40]$ & 0.07 & 1.000 \\
\hline Empathy & $5.18(1.32)[5.02,5.34]$ & $3.74(1.92)[3.52,3.95]$ & 0.87 & $<.001$ & 4.42 (1.69) [4.19, 4.62] & 0.52 & $<.001$ \\
\hline Social Connectedness & $4.10(1.66)[3.91,4.27]$ & $3.02(1.74)[2.84,3.22]$ & 0.64 & $<.001$ & $3.59(1.67)[3.37,3.82]$ & 0.30 & .005 \\
\hline Competence & $4.52(1.52)[4.33,4.70]$ & $4.46(1.59)[4.29,4.64]$ & 0.04 & 1.000 & $4.96(1.35)[4.75,5.13]$ & -0.30 & .019 \\
\hline Positive Affect (adjusted mean) & $3.92(0.84)[3.82,4.02]$ & $3.63(0.84)[3.54,3.72]$ & 0.35 & $<.001$ & $3.77(0.87)[3.65,3.89]$ & 0.13 & 1.000 \\
\hline Negative Affect (adjusted mean) & $2.19(0.69)[2.11,2.26]$ & $2.23(0.69)[2.15,2.31]$ & 0.07 & 1.000 & $2.23(0.68)[2.08,2.38]$ & 0.08 & 1.000 \\
\hline COVID-19 Intrusion Frequency & $2.41(2.73)[2.11,2.76]$ & $2.64(3.13)[2.30,2.99]$ & -0.08 & 1.000 & $2.71(3.09)[2.31,3.18]$ & -0.10 & 1.000 \\
\hline $\begin{array}{l}\text { Self-reported COVID-19 } \\
\text { Intrusions }\end{array}$ & $2.30(1.11)[2.17,2.44]$ & $2.35(1.17)[2.23,2.49]$ & -0.04 & 1.000 & $2.40(1.18)[2.24,2.57]$ & -0.08 & 1.000 \\
\hline COVID-19 Worry & $1.53(0.97)[1.41,1.64]$ & $1.63(0.94)[1.53,1.74]$ & -0.10 & 1.000 & $1.70(0.95)[1.57,1.84]$ & -0.17 & .789 \\
\hline COVID-19 Fear & $0.79(0.72)[0.70,0.87]$ & $0.80(0.72)[0.72,0.88]$ & -0.02 & 1.000 & $0.86(0.77)[0.76,0.98]$ & -0.11 & 1.000 \\
\hline
\end{tabular}

Note: Cohen's $d$ was calculated using means and S.D.s from the two conditions ( $d>0$ : prosocial $>$ proself). Intrusion frequency refers to counts of intrusions during the 2-minute intrusion monitoring task; self-reported intrusions refer to post-task self-reported intrusions. 
Table 4. Experiment 2, COVID-19-Unrelated conditions. Means, SDs, 95\% CIs, and Cohen's $d$ estimates for pre-registered outcome comparisons, Bonferroni corrected $p$-values were reported.

\begin{tabular}{|c|c|c|c|c|c|c|c|}
\hline \multirow[t]{2}{*}{ Outcome measurements } & \multirow[t]{2}{*}{ Prosocial $(n=288)$} & \multicolumn{3}{|c|}{ Including Proself Opt-out } & \multicolumn{3}{|c|}{ Excluding Proself Opt-out } \\
\hline & & Proself $(n=335)$ & $d$ & $p_{\text {corr }}$ & Proself $(n=185)$ & $d$ & $p_{\text {corr }}$ \\
\hline Positive Outcomes & $4.92(1.31)[4.74,5.05]$ & $3.35(1.28)[3.22,3.49]$ & 1.21 & $<.001$ & $3.60(1.28)[3.41,3.80]$ & 1.01 & $<.001$ \\
\hline Happiness & $4.89(1.57)[4.70,5.06]$ & $4.12(1.57)[3.94,4.28]$ & 0.49 & $<.001$ & $4.39(1.51)[4.17,4.61]$ & 0.32 & .004 \\
\hline Meaningfulness & $5.03(1.54)[4.85,5.20]$ & $3.36(1.75)[3.17,3.53]$ & 1.01 & $<.001$ & $3.72(1.74)[3.46,3.97]$ & 0.81 & $<.001$ \\
\hline Positive Impact & $5.35(1.32)[5.19,5.49]$ & $3.82(1.72)[3.64,4.01]$ & 0.99 & $<.001$ & $4.21(1.67)[3.94,4.44]$ & 0.78 & $<.001$ \\
\hline Empathy & $5.28(1.49)[5.08,5.43]$ & $2.41(1.51)[2.26,2.58]$ & 1.91 & $<.001$ & $2.57(1.51)[2.32,2.78]$ & 1.81 & $<.001$ \\
\hline Social Connectedness & $4.33(1.73)[4.11,4.52]$ & $2.38(1.59)[2.21,2.55]$ & 1.18 & $<.001$ & $2.61(1.63)[2.37,2.85]$ & 1.02 & $<.001$ \\
\hline Competence & $4.62(1.60)[4.41,4.78]$ & $4.00(1.65)[3.82,4.17]$ & 0.38 & $<.001$ & $4.14(1.60)[3.90,4.36]$ & 0.30 & $<.001$ \\
\hline Positive Affect (adjusted mean) & $4.13(0.90)[4.03,4.23]$ & $3.71(0.90)[3.61,3.81]$ & 0.47 & $<.001$ & $3.83(0.92)[3.70,3.97]$ & 0.30 & .013 \\
\hline Negative Affect (adjusted mean) & $2.09(0.78)[2.01,2.18]$ & $2.03(0.78)[1.94,2.12]$ & 0.08 & 1.000 & $2.15(0.76)[1.99,2.30]$ & 0.11 & 1.000 \\
\hline COVID-19 Intrusion Frequency & $2.47(2.69)[2.21,2.78]$ & $2.12(2.53)[1.87,2.42]$ & 0.13 & 1.000 & $2.20(2.45)[1.85,2.56]$ & 0.10 & 1.000 \\
\hline $\begin{array}{l}\text { Self-reported COVID-19 } \\
\text { Intrusions }\end{array}$ & $2.40(1.16)[2.27,2.53]$ & $2.26(1.11)[2.15,2.38]$ & 0.12 & 1.000 & $2.30(1.08)[2.14,2.46]$ & 0.09 & 1.000 \\
\hline COVID-19 Worry & $1.68(0.91)[1.56,1.79]$ & $1.61(0.97)[1.50,1.71]$ & 0.07 & 1.000 & $1.72(0.94)[1.59,1.85]$ & -0.05 & 1.000 \\
\hline COVID-19 Fear & $0.87(0.71)[0.78,0.95]$ & $0.87(0.74)[0.79,0.96]$ & -0.005 & 1.000 & $0.94(0.74)[0.83,1.05]$ & -0.09 & 1.000 \\
\hline
\end{tabular}

Note: Cohen's $d$ was calculated using means and S.D.s from the two conditions ( $d>0$ : prosocial $>$ proself). Intrusion frequency refers to counts of intrusions during the 2-minute intrusion monitoring task; self-reported intrusions refer to post-task self-reported intrusions. 
PROSOCIALITY PROMOTES WELL-BEING DURING COVID-19

\section{General Discussion}

Supporting the public's mental health and emotional well-being is of paramount importance during a global pandemic when many people are under chronic stress, heightened anxiety and depression (Holmes et al., 2020). With many common sources of well-being and stress reduction being minimized or discouraged to slow the spread of the virus (e.g., inperson communication), people require alternative methods to find happiness, connection, and meaning. In two experiments, we found that online forms of prosocial behavior led to greater positive psychological outcomes (empathy, social connectedness), and greater positive affect than non-prosocial behavior in Experiment 1 and, than proself behavior in Experiment 2. These findings provide novel evidence that small acts of kindness may benefit helpers by bolstering their well-being and psychological resources when facing adversity and a global pandemic.

To our knowledge, this is the first work to probe whether the emotional benefits of prosocial behavior vary as a function of alignment with a source of concern or stressor. In Experiment 2, we showed that when proself opt-out participants were included, prosocial behavior led to greater positive affect and positive psychological outcomes than proself behavior in both COVID-19-related (except for competence) and COVID-19-unrelated conditions. However, when proself opt-out participants were excluded, prosocial behavior's emotional benefits (i.e., greater positive affect and positive psychological outcomes) emerged only in the COVID-19-unrelated condition. When prosocial acts involved PPEs as in the COVID-19-related conditions, the benefits of prosocial (vs. proself) action were detectable only on empathy and social connectedness.

The attenuated benefits of COVID-19-related prosocial behavior could be due to the high perceived value and the scarcity of PPEs during the pandemic. While items available for purchase in the COVID-19-related and -unrelated conditions were worth the same value of $\$ 1$ 
PROSOCIALITY PROMOTES WELL-BEING DURING COVID-19

USD, donating PPEs were associated with lower levels of positive affect than donating food/writing supplies. Indeed, PPEs could be perceived as more beneficial for personal use than the snacks or writing supplies given that they protect individuals from being infected. Moreover, PPEs were in extremely short supply when these experiments were conducted in April 2020 (Khazan, 2020), and this scarcity may have further contributed to the heightened perceived value of PPEs over other available items. Therefore, donating valuable yet scarce PPEs could involve greater self-cost, amplify participants' concerns of their own physical safety and thus anxiety. Together, this may induce egocentric thinking and selfish motives in the COVID-19-related prosocial condition, which could have dampened prosocial behavior's emotional benefit (Todd et al., 2015; Todd \& Simpson, 2016). Indeed, previous research suggests that prosocial actions motivated by selfish interests undermined the benefits of generous behavior (Hill \& Howell, 2014; Wiwad \& Aknin, 2017; see also Crocker et al., 2017; Konrath et al., 2012; Qu et al., 2020 on discussions of prosocial motives). Thus, this may help explain why the emotional benefits of prosocial behavior were attenuated in the COVID-19-related conditions.

Results from Experiment 2 also suggested that reading about COVID-19 may have exacted an emotional toll: compared to the COVID-19-unrelated conditions, participants in the COVID-19-related conditions reported lowered positive affect gains and smaller negative affect decreases, regardless of who they were spending on. These findings are consistent with previous research showing that media/news consumption of COVID-19 related information had a negative impact on mental well-being (Bu et al., 2020; Gao et al., 2020; Huckins et al., 2020). These findings are consistent with results from Experiment 1, wherein participants in the prosocial condition read additional COVID-19 information during the donation task and reported smaller negative affect decreases than participants in the non-prosocial control condition. Collectively, these results suggested that while people may already be inundated 
PROSOCIALITY PROMOTES WELL-BEING DURING COVID-19

with COVID-19 information during the pandemic, repeated reminders of the on-going pandemic may exact an additional toll. In contrast, diverting people's attention away from the pandemic to other information, even temporarily, may confer emotional benefits. Our results also suggest that prosocial acts, particularly when enacted for a cause that is not directly related to the pandemic, could be a fruitful avenue for improving well-being during a pandemic.

It is important to emphasize that prosocial action did not lead to larger reductions in negative affect than proself behavior, nor did prosocial action alleviated negative psychological outcomes, such as intrusive thoughts, as well as fear and worry related to COVID-19. This finding is consistent with past research and theorizing demonstrating that positive affect and negative affect are independent components of subjective well-being (Diener \& Emmons, 1984; Diener, 2000) and exist on orthogonal dimensions (Watson \& Tellegen, 1985). Therefore, an enhancement of positive affect does not necessitate or imply reductions in negative affect. Supporting this possibility, past research shows that prosocial behavior is more strongly linked with positive emotions than negative emotions (e.g., Curry et al., 2018; Hui et al., 2020; Jebb et al., 2020; Kushlev et al., 2020 preprint). Indeed, past work on prosocial spending typically finds that spending money on others consistently leads to benefits in positive emotions, while declines in negative emotions are less consistent, even mixed (e.g., Aknin et al., 2012; Aknin et al., 2018). It is possible that the current global context may also be a source of stability for negative emotions: fear and worry may be more resistant to change because of the chronic stress and imminent threat posed by the pandemic.

One precaution in generalizing the present findings is that we found meaningful differences between opt-out and opt-in participants in Experiment 2. Specifically, in both COVID-19-related and -unrelated prosocial conditions, participants who chose to opt-out of engaging in a prosocial act reported lower empathetic concern scores than participants who 
PROSOCIALITY PROMOTES WELL-BEING DURING COVID-19

opted-in and engaged in a prosocial act. Moreover, across both prosocial and proself conditions, opt-out participants reported less impact of the COVID-19 (see Tables S2-3). While these individual differences could help explain why some participants engaged or disengaged from the prosocial or proself behavior, it remains an intriguing question whether prosocial behavior's emotional benefits may only be evident among people with higher empathic tendencies (see Hill \& Howell, 2014, Wiwad \& Aknin, 2017). Our supplementary analyses (see Supplemental Materials) suggested that as long as people voluntarily engage in prosocial acts, prosocial behavior's emotional benefits were not modulated by individual differences of empathetic concerns and by perception of COVID-19 impact. However, given the exploratory nature of the analyses, future evidence is required to draw conclusions.

One possible limitation of the present work is that we only recruited participants from the United States (US), which may raise questions regarding the generalizability of these findings. The US had some of the highest rates of COVID-19 infection and COVID-19 related deaths since March 26, 2020, especially at the time of data collection (Johns Hopkins University, 2020). As a result, the heightened fear and anxiety surrounding the COVID-19 pandemic provides a theoretically rich backdrop for studying the potential benefits of prosocial behavior. While the present work suggests that prosocial behavior leads to emotional benefits even during the heightened stress of the pandemic, future work should test whether these results generalize to other regions and contexts. We suspect that similar results may emerge elsewhere because the well-being benefits of prosociality have been detected in a variety of different populations and cultural contexts around the world (Aknin et al., 2013). Furthermore, the present studies were preregistered with high statistical power and predetermined analytical plans, which is likely to increase their replicability.

Another limitation of this work concerns the nature of our prosociality manipulations. Admittedly, the prosocial behaviors enacted in Experiments 1 and 2 were relatively low cost 
PROSOCIALITY PROMOTES WELL-BEING DURING COVID-19

in that participants only spent $5 \varnothing$ US to donate $\$ 1$ USD worth of goods. On a practical level, this relatively small donation was required so that we could afford to recruit sufficiently large and well-powered samples. Moreover, this detail is consistent with past research wherein large numbers of online participants were provided with the opportunity to make \$1 USD donations or purchase a small item for themselves (Hanniball et al., 2019). Theoretically, the low-cost donations provide a conservative test of our hypothesis (Prentice \& Miller, 1992). Future research could test whether these effects generalize to high-cost prosocial behavior enacted during the pandemic. Importantly, however, generous action should not come at the expense of personal safety: risky or excessive generosity can have negative consequences, such as making people feel exhausted and leading to deteriorated mental health (e.g., Cameron \& Payne, 2011; Falk \& Graeber, 2020; Tei et al., 2014).

Along similar lines, our manipulation of COVID-19 relevance may have not been as clear cut as intended. Indeed, we hypothesized that PPEs were more related to the COVID-19 pandemic than snacks or writing supplies given that the PPEs can protect individuals from being infected by the virus. However, as we note in the introduction, COVID-19 has altered numerous aspects of daily life, such that providing snacks and writing supplies to needy children who were unable to attend school due to closures are not irrelevant forms of helping during the strain of a pandemic. Indeed, various disparities in food and educational access were amplified during the COVID-19 pandemic, meaning that these forms of aid may have been psychologically related to COVID-19. Future research, ideally looking at large and realworld demonstrations of generosity, and prosocial behavior's perceived relatedness with COVID-19, will further elucidate this relationship.

Despite these limitations, our results add to recent research underscoring the importance of prosociality during the COVID-19 pandemic (Brooks et al., 2020; Van Bavel et al., 2020). Our experimental findings converge with recent evidence from a diary study 
PROSOCIALITY PROMOTES WELL-BEING DURING COVID-19

conducted during the COVID-19 pandemic wherein daily helping behavior was associated with higher levels of positive affect (Sin et al., 2020). Recent work has shown that people with higher prosocial motives were more willing to comply with preventive behavior (e.g., physical distancing, Jordan et al., 2021). Enhanced empathy and social connectedness, induced by prosocial behavior, could also motivate people to engage in protective behavior for those vulnerable people (Pfattheicher et al., 2020). Thus, emphasizing prosocial information during this pandemic could have broader social implications in combatting COVID-19 beyond promoting positive affect at an individual level.

Prosocial behavior has been suggested as an effective intervention to protect mental well-being during the unprecedented global pandemic (Holmes et al., 2020). Our research provides the first causal evidence for this argument by demonstrating that generous action leads to higher levels of positive affect during the COVID-19 pandemic than self-directed action. One practical way to implement the present findings is to encourage greater prosocial behavior at a systemic level. For instance, government funding could be used to support social service programs (e.g., job training, food banks etc.) that enable people to help others and improve the well-being of individuals in our society (Aknin \& Whillans, 2020). At a societal level, promoting prosocial behavior not only brings emotional benefits to individuals, but could also increase social connectedness and cohesiveness. Future studies may provide deeper insight into how humans may experience positive emotion during a global pandemic via social solidarity- and possibly emerge kinder and happier than they were before. 


\section{Data and code availability:}

https://osf.io/e3kdr

\section{Acknowledgment}

We thank the action editor and the anonymous reviewers for their constructive comments on the manuscript. We thank Yiwen Zhong for her help on the manuscript. This research was supported by the National Natural Science Foundation of China (No. 31922089), General Research Fund (No. 17601318) of Hong Kong Research Grants Council, Technology Planning Project of Guangdong Province of China (No. 2019A050510048), and Key Realm R\&D Program of Guangzhou (No. 20200703005).

\section{Conflict of Interests}

The authors declare no conflict of interests. 
PROSOCIALITY PROMOTES WELL-BEING DURING COVID-19

\section{References}

Ahorsu, D. K., Lin, C.-Y., Imani, V., Saffari, M., Griffiths, M. D., \& Pakpour, A. H. (2020). The Fear of COVID-19 Scale: Development and Initial Validation. International Journal of Mental Health and Addiction, 18, 1-9. https://doi.org/10.1007/s11469-02000270-8

Aknin, L. B., Barrington-Leigh, C. P., Dunn, E. W., Helliwell, J. F., Burns, J., BiswasDiener, R., Kemeza, I., Nyende, P., Ashton-James, C. E., \& Norton, M. I. (2013). Prosocial spending and well-being: Cross-cultural evidence for a psychological universal. Journal of Personality and Social Psychology, 104(4), 635-652. https://doi.org/10.1037/a0031578

Aknin, L. B., Broesch, T., Hamlin, J. K., \& Van de Vondervoort, J. W. (2015). Prosocial behaviour leads to happiness in a small-scale rural society. Journal of Experimental Psychology: General, 144(4), 788-795. https://doi.org/10.1037/xge0000082

Aknin, L. B., Hamlin, J.K. \& Dunn, E. W. (2012). Giving leads to happiness in young children. PLoS ONE, 7(6), e39211. DOI: 10.1371/journal.pone.0039211

Aknin, L. B., Dunn, E. W., Proulx, J., Lok, I., \& Norton, M. I. (2020). Does spending money on others promote happiness?: A registered replication report. Journal of Personality and Social Psychology, 119(2), e15-e26. https://doi.org/10.1037/pspa0000191

Aknin, L. B., Van de Vondervoort, J. W., \& Hamlin, J. K. (2018). Positive feelings reward and promote prosocial behaviour. Current Opinion in Psychology, 20, 55-59. https://doi.org/10.1016/j.copsyc.2017.08.017

Aknin, L.B. and Whillans, A.V. (2020). Helping and happiness: A review and guide for public policy. Social Issues and Policy Review, 15(1), 3-

34. https://doi.org/10.1111/sipr.12069

Altena, E., Baglioni, C., Espie, C. A., Ellis, J., Gavriloff, D., Holzinger, B., Schlarb, A., 
PROSOCIALITY PROMOTES WELL-BEING DURING COVID-19

Frase, L., Jernelöv, S., \& Riemann, D. (2020). Dealing with sleep problems during home confinement due to the COVID-19 outbreak: Practical recommendations from a task force of the European CBT-I Academy. Journal of Sleep Research, 29:e13052. https://doi.org/10.1111/jsr.13052

Bomyea, J., \& Lang, A. J. (2016). Accounting for intrusive thoughts in PTSD: Contributions of cognitive control and deliberate regulation strategies. Journal of Affective Disorders, 192, 184-190. https://doi.org/10.1016/j.jad.2015.12.021

Brooks, S. K., Webster, R. K., Smith, L. E., Woodland, L., Wessely, S., Greenberg, N., \& Rubin, G. J. (2020). The psychological impact of quarantine and how to reduce it: rapid review of the evidence. The Lancet, 395(10227), 912-920. https://doi.org/10.1016/S0140-6736(20)30460-8

Bu, F., Steptoe, A., \& Fancourt, D. (2020). Loneliness during lockdown: Trajectories and predictors during the COVID-19 pandemic in 35,712 adults in the UK. MedRxiv, https://doi.org/10.1101/2020.05.29.20116657

Burkart, J. M., Allon, O., Amici, F., Fichtel, C., Finkenwirth, C., Heschl, A., . . Martins, E. (2014). The evolutionary origin of human hyper-cooperation. Nature Communications, 5(1), 1-9. https://doi.org/10.1038/ncomms5747

Butler, P. (2020, April 13). A million volunteer to help NHS and others during Covid-19 outbreak. Retrieved May 17, 2020, from https://www.theguardian.com/society/2020/apr/13/a-million-volunteer-to-help-nhsand-others-during-covid-19-lockdown

Buysse, D. J., Reynolds III, C. F., Monk, T. H., Berman, S. R., \& Kupfer, D. J. (1989). The 
PROSOCIALITY PROMOTES WELL-BEING DURING COVID-19

Pittsburgh Sleep Quality Index: a new instrument for psychiatric practice and research. Psychiatry Research, 28(2), 193-213. https://doi.org/10.1016/01651781(89)90047-4

Cameron, C. D., \& Payne, B. K. (2011). Escaping affect: how motivated emotion regulation creates insensitivity to mass suffering. Journal of Personality and Social Psychology, 100(1), 1-15. https://doi.org/10.1037/a0021643

Cialdini, R. B., \& Kenrick, D. T. (1976). Altruism as hedonism: a social development perspective on the relationship of negative mood state and helping. Journal of Personality and Social Psychology, 34(5), 907-914. https://doi.org/10.1037/00223514.34.5.907.

Crocker, J., Canevello, A., \& Brown, A. A. (2017). Social motivation: Costs and benefits of selfishness and otherishness. Annual Review of Psychology, 68, 299-325. https://doi.org/10.1146/annurev-psych-010416-044145

Curry, O. S., Rowland, L. A., Van Lissa, C. J., Zlotowitz, S., McAlaney, J., \& Whitehouse, H. (2018). Happy to help? A systematic review and meta-analysis of the effects of performing acts of kindness on the well-being of the actor. Journal of Experimental Social Psychology, 76, 320-329. https://doi.org/10.1016/j.jesp.2018.02.014

Davis, M. H. (1980). A multidimensional approach to individual differences in empathy. Catalog of Selected Documents in Psychology, 10, 85, 1-17.

Diener, E. (2000). Subjective well-being: The science of happiness and a proposal for a national index. American Psychologist, 55(1), 34-43. https://doi.org/10.1037/0003066X.55.1.34

Diener, E., \& Emmons, R. A. (1984). The independence of positive and negative affect. Journal of Personality and Social Psychology, 47(5), 1105-1117. https://doi.org/10.1037/0022-3514.47.5.1105 
PROSOCIALITY PROMOTES WELL-BEING DURING COVID-19

Dienes, Z. (2014). Using Bayes to get the most out of non-significant results. Frontiers in Psychology, 5, 781 .

Doré, B. P., Morris, R. R., Burr, D. A., Picard, R. W., \& Ochsner, K. N. (2017). Helping others regulate emotion predicts increased regulation of one's own emotions and decreased symptoms of depression. Personality and Social Psychology Bulletin, 43(5), 729-739. https://doi.org/10.1177/0146167217695558

Dunn, E. W., Aknin, L. B., \& Norton, M. I. (2008). Spending money on others promotes happiness. Science, 319(5870), 1687-1688. https://doi.org/10.1126/science.1150952

Dunn, E. W., Aknin, L. B., \& Norton, M. I. (2014). Prosocial spending and happiness: Using money to benefit others pays off. Current Directions in Psychological Science, 23(1), 41-47. https://doi.org/10.1177/0963721413512503

Falk, A., \& Graeber, T. (2020). Delayed negative effects of prosocial spending on happiness. Proceedings of the National Academy of Sciences, 117(12), 6463-6468. https://doi.org/10.1073/pnas.1914324117

Fancourt, D., Steptoe, A., \& Bu, F. (2020). Trajectories of anxiety and depressive symptoms during enforced isolation due to COVID-19 in England: a longitudinal observational study. The Lancet Psychiatry, 8(2), 141-149. https://doi.org/10.1016/S22150366(20)30482-X

Frazier, P., Greer, C., Gabrielsen, S., Tennen, H., Park, C., \& Tomich, P. (2013). The relation between trauma exposure and prosocial behaviour. Psychological Trauma: Theory, Research, Practice, and Policy, 5(3), 286-294. https://doi.org/10.1037/a0027255

Freeman, D., Bird, J. C., Loe, B. S., Kingdon, D., Startup, H., Clark, D. M., Ehlers, A., Černis, E., Wingham, G., Evans, N., Lister, R., Pugh, K., Cordwell, J., \& Dunn, G. (2019). The Dunn Worry Questionnaire and the Paranoia Worries Questionnaire: new 
PROSOCIALITY PROMOTES WELL-BEING DURING COVID-19

assessments of worry. Psychological Medicine, 50(5), 771-780.

https://doi.org/10.1017/s0033291719000588

Galak, J., Small, D., \& Stephen, A. T. (2011). Microfinance decision making: A field study of prosocial lending. Journal of Marketing Research, 48(SPL), S130-S137. https://doi.org/10.1509/jmkr.48.SPL.S130

Gao, J., Zheng, P., Jia, Y., Chen, H., Mao, Y., Chen, S., Wang, Y., Fu, H., \& Dai, J. (2020). Mental health problems and social media exposure during COVID-19 outbreak. PLOS ONE, 15(4), e0231924. https://doi.org/10.1371/journal.pone.0231924

Giving USA Foundation. (2006). Giving USA 2019: The Annual Report on Philanthropy for the Year 2018. Giving USA Foundation.

Gruber, J., Prinstein, M. J., Abramowitz, J. S., Albano, A. M., Aldao, A., Borelli, J. L., Anna Clark, L., Davila, J., Forbes, E. E., Gee, D. G., Nagayama Hall, G. C., Hallion, L. S., Hinshaw, S. P., Hofmann, S. G., Hollon, S. D., Joormann, J., Kazdin, A. E., Klein, D. N., Levenson, R. W., ... Weinstock, L. (2020). Mental health and clinical psychological science in the time of COVID-19: Challenges, opportunities, and a call to action. American Psychologist. https://doi.org/10.1037/amp0000707

Hanniball, K. B., Aknin, L. B., Douglas, K. S., \& Viljoen, J. L. (2019). Does helping promote well-being in at-risk youth and ex-offender samples? Journal of Experimental Social Psychology, 82, 307-317. https://doi.org/10.1016/j.jesp.2018.11.001

Hill, G., \& Howell, R. T. (2014). Moderators and mediators of pro-social spending and wellbeing: The influence of values and psychological need satisfaction. Personality and Individual Differences, 69, 69-74. https://doi.org/10.1016/j.paid.2014.05.013

Holmes, E. A., O’Connor, R. C., Perry, V. H., Tracey, I., Wessely, S., Arseneault, L., Ballard, C., Christensen, H., Cohen Silver, R., Everall, I., Ford, T., John, A., Kabir, T., King, K., Madan, I., Michie, S., Przybylski, A. K., Shafran, R., Sweeney, A., ... 
PROSOCIALITY PROMOTES WELL-BEING DURING COVID-19

Bullmore, E. (2020). Multidisciplinary research priorities for the COVID-19 pandemic: a call for action for mental health science. The Lancet Psychiatry, 7(6), 547-560. https://doi.org/10.1016/s2215-0366(20)30168-1

Hu, X., Bergström, Z. M., Gagnepain, P., \& Anderson, M. C. (2017). Suppressing unwanted memories reduces their unintended influences. Current Directions in Psychological Science, 26(2), 197-206. https://doi.org/10.1177/0963721417689881

Huang, Y., \& Zhao, N. (2020). Generalized anxiety disorder, depressive symptoms and sleep quality during COVID-19 outbreak in China: a web-based cross-sectional survey. Psychiatry Research, 112954. https://doi.org/10.1016/j.psychres.2020.112954

Huckins, J. F., DaSilva, A. W., Wang, W., Hedlund, E., Rogers, C., Nepal, S. K., Wu, J., Obuchi, M., Murphy, E. I., Meyer, M. L., Wagner, D. D., Holtzheimer, P. E., \& Campbell, A. T. (2020). Mental Health and Behaviour During the Early Phases of the COVID-19 Pandemic: A Longitudinal Mobile Smartphone and Ecological Momentary Assessment Study in College Students. Journal of Medical Internet Research, 22(6), e20185. https://doi.org/10.2196/20185

Hui, B. P., Ng, J. C., Berzaghi, E., Cunningham-Amos, L. A., \& Kogan, A. (2020). Rewards of kindness? A meta-analysis of the link between prosociality and wellbeing. Psychological Bulletin, 146(12), 1084-1116. https://doi.org/10.1037/bul0000298

Humphreys, K. L., Myint, M. T., \& Zeanah, C. H. (2020). Increased risk for family violence during the COVID-19 pandemic. Pediatrics, 146(1), e20200982. https://doi.org/10.1542/peds.2020-0982

Jebb, A. T., Morrison, M., Tay, L., \& Diener, E. (2020). Subjective Well-Being Around the World: Trends and Predictors Across the Life Span. Psychological Science, 31(3), 293-305. https://doi.org/10.1177/0956797619898826 
PROSOCIALITY PROMOTES WELL-BEING DURING COVID-19

Johns Hopkins Coronavirus Resource Center. (2020). Retrieved from https://coronavirus.jhu.edu

Jordan, J. J., Yoeli, E., \& Rand, D. G. (2021). Don't get it or don't spread it: Comparing selfinterested versus prosocial motivations for COVID-19 prevention behaviors. Scientific Reports, 11(1), 1-17.

Keith, T., \& Gharib, M. (2020, April 15). A Timeline of Coronavirus Comments from President Trump and WHO. https://www.npr.org/sections/2020/04/15

Khazan, O. (2020, May 15). Why We're Running Out of Masks in the Coronavirus Crisis. The Atlantic. https://www.theatlantic.com/health/archive/2020/04/why-were-runningout-of-masks-in-the-coronavirus-crisis/609757/

Klein, N. (2017). Prosocial behaviour increases perceptions of meaning in life. The Journal of Positive Psychology, 12(4), 354-361. https://doi.org/10.1080/17439760.2016.1209541

Kogut, T., \& Ritov, I. (2005). The “identified victim” effect: An identified group, or just a single individual?. Journal of Behavioural Decision Making, 18(3), 157-167. https://doi.org/10.1002/bdm.492

Konrath, S., Fuhrel-Forbis, A., Lou, A., \& Brown, S. (2012). Motives for volunteering are associated with mortality risk in older adults. Health Psychology, 31(1), 87-96. https://doi.org/10.1037/a0025226

Kushlev, K., Radosic, N., \& Diener, E. (2020). Subjective Well-Being and Prosociality Around the Globe: Happy People Give More of Their Time and Money to Others. Retrieved from https://psyarxiv.com/7wzan/

LeBlanc, P., Hoffman, J., \& Liptak, K. (2020, March 30). Trump extends federal social distancing guidelines to April 30. Retrieved May 10, 2020, from 
PROSOCIALITY PROMOTES WELL-BEING DURING COVID-19

https://edition.cnn.com/2020/03/29/politics/trump-coronavirus-pressconference/index.html

Lowe, S., \& Fothergill, A. (2003). A need to help: Emergent volunteer behaviour after September 11th. Beyond September 11th: An account of post-disaster research, 293314.

Lovibond, P. F., \& Lovibond, S. H. (1995). The structure of negative emotional states: Comparison of the Depression Anxiety Stress Scales (DASS) with the Beck Depression and Anxiety Inventories. Behaviour Research and Therapy, 33(3), 335343. https://doi.org/10.1016/0005-7967(94)00075-U

Luciano, J. V., Algarabel, S., Tomás, J. M., \& Martínez, J. L. (2005). Development and validation of the thought control ability questionnaire. Personality and Individual Differences, 38(5), 997-1008. https://doi.org/10.1016/j.paid.2004.06.020

Marks, E. H., Franklin, A. R., \& Zoellner, L. A. (2018). Can't get it out of my mind: A systematic review of predictors of intrusive memories of distressing events. Psychological Bulletin, 144(6), 584-640. https://doi.org/10.1037/bul0000132

NCHS (2020). Household Pulse Survey - COVID-19. Retrieved June 03, 2020, from https://www.cdc.gov/nchs/covid19/pulse/mental-health.htm

Nelson, S. K., Layous, K., Cole, S. W., \& Lyubomirsky, S. (2016). Do unto others or treat yourself? The effects of prosocial and self-focused behaviour on psychological $f$ lourishing. Emotion, 16(6), 850-861. https://doi.org/10.1037/emo0000178

Pennycook, G., McPhetres, J., Zhang, Y., Lu, J. G., \& Rand, D. G. (2020). Fighting COVID19 misinformation on social media: Experimental evidence for a scalable accuracynudge intervention. Psychological Science, 31(7), 770-780. https://doi.org/10.1177/0956797620939054

Pfattheicher, S., Nockur, L., Böhm, R., Sassenrath, C., \& Petersen, M. B. (2020). 
PROSOCIALITY PROMOTES WELL-BEING DURING COVID-19

The Emotional Path to Action: Empathy Promotes Physical Distancing and Wearing of Face Masks During the COVID-19 Pandemic. Psychological Science, 31(11), 1363-1373. https://doi.org/10.1177/0956797620964422

Pfefferbaum, B., \& North, C. S. (2020). Mental health and the Covid-19 pandemic. New England Journal of Medicine, 383, 510-512. https://doi.org/10.1056/NEJMp2008017

Poulin, M. J., Brown, S. L., Dillard, A. J., \& Smith, D. M. (2013). Giving to others and the association between stress and mortality. American Journal of Public Health, 103(9), 1649-1655. https://doi.org/10.2105/AJPH.2012.300876

Prentice, D. A., \& Miller, D. T. (1992). When small effects are impressive. Psychological Bulletin, 112(1), 160-164. https://doi.org/10.1037/0033-2909.112.1.160

Qu, H., Konrath, S., \& Poulin, M. (2020). Which types of giving are associated with reduced mortality risk among older adults? Personality and Individual Differences, 154, 109668. https://doi.org/10.1016/j.paid.2019.109668

Rao, L.-L., Han, R., Ren, X.-P., Bai, X.-W., Zheng, R., Liu, H., Wang, Z.-J., Li, J.-Z., Zhang, K., \& Li, S. (2011). Disadvantage and prosocial behaviour: the effects of the Wenchuan earthquake. Evolution and Human Behaviour, 32(1), 63-69. https://doi.org/10.1016/j.evolhumbehav.2010.07.002

Raposa, E. B., Laws, H. B., \& Ansell, E. B. (2016). Prosocial behaviour mitigates the negative effects of stress in everyday life. Clinical Psychological Science, 4(4), 691698. https://doi.org/10.1177/2167702615611073

Rodriguez, H., Trainor, J., \& Quarantelli, E. L. (2006). Rising to the challenges of a catastrophe: The emergent and prosocial behaviour following Hurricane Katrina. The annals of the American academy of political and social science, 604(1), 82-101. https://doi.org/10.1177/0002716205284677

Rosenfeld, D. L., Balcetis, E., Bastian, B., Berkman, E. T., Bosson, J. K., Brannon, T. 
PROSOCIALITY PROMOTES WELL-BEING DURING COVID-19

N., Burrow, A. L., Cameron, C. D., Chen, S., Cook, J. E., Crandall, C. S., Davidai, S., Dhont, K., Eastwick, P. W., Gaither, S. E., Gangestad, S. W., Gilovich, T., Gray, K., Haines, E. L., . . Tomiyama, A. J. (2021). Psychological science in the wake of COVID-19: Social, methodological, and meta-scientific considerations. Perspectives on Psychological Science.

Sandford, A. (2020, April 3). Coronavirus: Half of humanity now on lockdown as 90 countries call for confinement. Retrieved January 5, 2021, from https://www.euronews.com/2020/04/02/coronavirus-in-europe-spain-s-death-toll-hits10-000-after-record-950-new-deaths-in-24-hou

Sin, N. L., Klaiber, P., Wen, J. H., \& DeLongis, A. (2020). Helping Amid the Pandemic: Daily Affective and Social Implications of COVID-19-Related Prosocial Activities. The Gerontologist, 61(1), 59-70. https://doi.org/10.1093/geront/gnaa140

Takarangi, M. K., Strange, D., \& Lindsay, D. S. (2014). Self-report may underestimate trauma intrusions. Consciousness and Cognition, 27, 297-305. https://doi.org/10.1016/j.concog.2014.06.002

Tei, S., Becker, C., Kawada, R., Fujino, J., Jankowski, K. F., Sugihara, G., Murai, T., \& Takahashi, H. (2014). Can we predict burnout severity from empathy-related brain activity? Translational Psychiatry, 4(6), e393. https://doi.org/10.1038/tp.2014.34

Todd, A. R., Forstmann, M., Burgmer, P., Brooks, A. W., \& Galinsky, A. D. (2015). Anxious and egocentric: How specific emotions influence perspective taking. Journal of Experimental Psychology: General, 144(2), 374. https://doi.org/10.1037/xge0000048

Todd, A. R., \& Simpson, A. J. (2016). Anxiety impairs spontaneous perspective calculation: Evidence from a level-1 visual perspective-taking task. Cognition, 156, 88-94. https://doi.org/10.1016/j.cognition.2016.08.004 
PROSOCIALITY PROMOTES WELL-BEING DURING COVID-19

Tull, M. T., Edmonds, K. A., Scamaldo, K., Richmond, J. R., Rose, J. P., \& Gratz, K. L. (2020). Psychological Outcomes Associated with Stay-at-Home Orders and the Perceived Impact of COVID-19 on Daily Life. Psychiatry Research, 113098. https://doi.org/10.1016/j.psychres.2020.113098

Van Bavel, J. J., Baicker, K., Boggio, P. S., Capraro, V., Cichocka, A., Cikara, M., Crockett, M. J., Crum, A. J., Douglas, K. M., Druckman, J. N., Drury, J., Dube, O., Ellemers, N., Finkel, E. J., Fowler, J. H., Gelfand, M., Han, S., Haslam, S. A., Jetten, J., ... Willer, R. (2020). Using social and behavioural science to support COVID-19 pandemic response. Nature Human Behaviour, 4(5), 460-471. https://doi.org/10.1038/s41562-020-0884-Z

Varma, M. M., Lin, X. L., Chen, D., Aknin, L. B., \& Hu, X. (2021, September 13). Prosocial behavior promotes positive emotion during the COVID-19 pandemic. Retrieved from osf.io/e $3 \mathrm{kdr}$

Varma, M. M., \& Hu, X. (in press). Prosocial behaviour reduces unwanted intrusions of experimental traumatic memories. Behaviour Research and Therapy, 103998. https://doi.org/10.1016/j.brat.2021.103998

Västfjäll, D., Slovic, P., Mayorga, M., \& Peters, E. (2014). Compassion fade: Affect and charity are greatest for a single child in need. PloS one, 9(6), e100115. https://doi.org/10.1371/journal.pone.0100115

Wang, Y., Ge, J., Zhang, H., Wang, H., \& Xie, X. (2020). Altruistic behaviours relieve physical pain. Proceedings of the National Academy of Sciences, 117(2), 950-958. https://doi.org/10.1073/pnas.1911861117

Watson, D., Clark, L. A., \& Tellegen, A. (1988). Development and validation of brief measures of positive and negative affect: the PANAS scales. Journal of Personality 
PROSOCIALITY PROMOTES WELL-BEING DURING COVID-19

and Social Psychology, 54(6), 1063-1070. https://doi.org/10.1037//00223514.54.6.1063

Watson, D., \& Tellegen, A. (1985). Toward a consensual structure of mood. Psychological Bulletin, 98(2), 219-235. https://doi.org/10.1037//0033-2909.98.2.219

Weinstein, N., \& Ryan, R. M. (2010). When helping helps: Autonomous motivation for prosocial behaviour and its influence on well-being for the helper and recipient. Journal of Personality and Social Psychology, 98(2), 222-244.

https://doi.org/10.1037/a0016984

Weiss, D. S. \& Marmar, C. R. (1997) The Impact of Event Scale - Revised. In Assessing Psychological Trauma and PTSD (eds Wilson, J. P. \& Keane, T. M.), pp. 399411. New York: Guilford Press.

Wiwad, D., \& Aknin, L. B. (2017). Motives matter: The emotional consequences of recalled self-and other-focused prosocial acts. Motivation and Emotion, 41(6), 730-740. https://doi.org/10.1007/s11031-017-9638-2

Zaki, J. (2020). Catastrophe compassion: Understanding and extending prosociality under crisis. Trends in Cognitive Sciences, 24(8), 587-589. https://doi.org/10.1016/j.tics.2020.05.006

Zoellner, L. A., Rothbaum, B. O., \& Feeny, N. C. (2011). PTSD not an anxiety disorder? DSM committee proposal turns back the hands of time. Depression and Anxiety, 28(10), 853-856. https://doi.org/10.1002/da.20899 
Supplement of

Prosocial behavior promotes positive emotion during the COVID-19 Pandemic

Table of Content

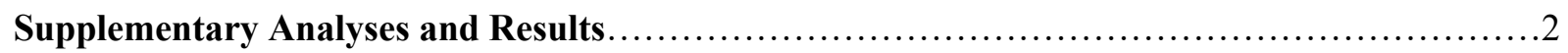

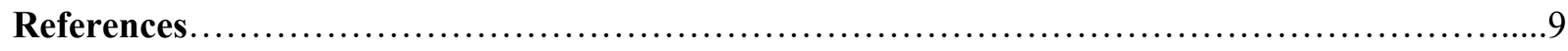

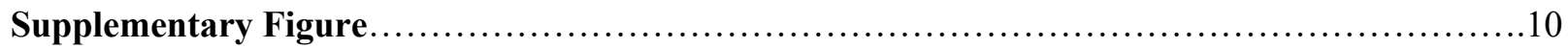

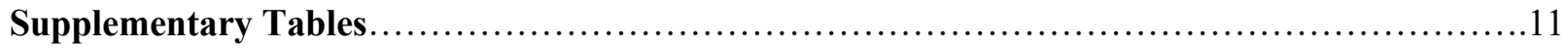




\section{Supplement Analyses and Results}

\section{Sample characteristics}

Information on sample demographics, COVID-19's psychological impact (e.g., perceived existential threats of COVID-19, concerns of physical/mental health due to COVID-19), sleep quality, and anxiety/depression/stress levels from Experiments 1 and 2 are provided in Tables S3 and S4, respectively. On average, participants reported moderate levels of anxiety, depression and stress levels based on conventional cutoffs of the DASS-21 scale (Lovibond \& Lovibond, 1995), with 29\% of the sample reporting moderate-to-extremely severe depression or anxiety levels. This is largely consistent with a nation-level Household Pulse Survey conducted by the National Center for Health Statistics between April 23 and May 5 2020, which showed that 35.9\% of the sample developed either depression or anxiety symptoms (NCHS, 2020). As a pre-pandemic benchmark, the same survey conducted in January - June 2019 showed that $11.0 \%$ of the sample showed either depression or anxiety symptoms (NCHS, 2020). Thus, participants in our sample reported similar levels of anxiety and depression to that observed nation-wide during approximately the same time, and significantly higher levels than observed before the COVID-19 pandemic.

\section{Experiment 1}

Preregistered Analyses:

Intrusion monitoring. Counter to pre-registered hypothesis, a one-tailed Mann-Whitney $U$ test revealed no significant difference between the two conditions on COVID-19 related intrusion frequencies during the 2-minute intrusion monitoring task, $W=17903, p=.807, d=0.08, \mathrm{BF}_{10}=$ 0.07 .

Self-reported intrusive thoughts. Counter to pre-registered hypothesis, an ANCOVA using baseline intrusion scores as covariates showed that post-task self-reported intrusions did not differ between the two conditions, $F(1,386)=0.10, p=.755, \eta_{\mathrm{p}}{ }^{2}<0.001, \mathrm{BF}_{10}=0.12, d=0.03$. 
Subjective worry and fear related to COVID-19. Counter to pre-registered hypothesis, a one-tailed Mann-Whitney $U$ tests revealed no significant difference on subjective worry, $W=17520, p=.884, d$ $=0.12, \mathrm{BF}_{10}=0.05$, nor subjective fear, $W=17656, p=.859, d=0.09, \mathrm{BF}_{10}=0.07$, across conditions.

Non-Preregistered Exploratory Analyses: Excluding only Bots and Duplicates $(N=423)$ :

We repeated our pre-registered analyses excluding bots, duplicates and prosocial opt-out participants, but including participants who failed attention checks. This resulted in 194 participants in the prosocial condition and 229 participants in the non-prosocial condition. Results were consistent with the main results reported in the manuscript: participants in the prosocial condition reported higher positive psychological outcomes $(W=9710, p<.001, d=1.11)$, higher positive affect $(F(1,420)=$ $7.34, p=.007, d=0.26)$, and higher negative affect $(F(1,420)=20.60, p<.001, d=0.44)$ than participants in the non-prosocial condition.

\section{Experiment 2}

Preregistered Confirmatory Analyses $N=1,234$ :

Intrusion monitoring. Counter to pre-registered hypothesis, intrusion monitoring did not differ among participants in proself and prosocial spending conditions in either COVID-19-related $(W=47654, p$ $\left.=.277, d=0.08, \mathrm{BF}_{10}=0.24\right)$ or COVID-19-unrelated $\left(W=44472, p=.957, d=0.13, \mathrm{BF}_{10}=0.04\right)$ conditions.

Self-reported intrusive thoughts. Counter to pre-registered hypothesis, self-reported intrusive thoughts did not differ among prosocial and proself participants in either the COVID-19-related ( $F$ $\left.(1,608)=0.56, p=.454, \eta_{\mathrm{p}}^{2}<0.001, \mathrm{BF}_{10}=0.12, d=0.06\right)$ or the COVID-19-unrelated $(F(1,620)$ $\left.=2.28, p=.131, \eta_{\mathrm{p}}{ }^{2}=0.004, \mathrm{BF}_{10}=0.27, d=0.12\right)$ conditions in the ANCOVA models using baseline intrusions as covariates. 
Subjective worry and fear related to COVID-19. In the COVID-19-related conditions, prosocial and proself participants did not differ in their subjective worry $\left(W=49250, p=.188, d=0.10, \mathrm{BF}_{10}=\right.$ $0.20)$, nor fear $\left(W=46681, p=.893, d=0.02, \mathrm{BF}_{10}=0.09\right)$. Similarly, in the COVID-19-unrelated condition, there were no significant differences between the proself and prosocial conditions on subjective worry $\left(W=46577, p=.457, d=0.07, \mathrm{BF}_{10}=0.13\right)$ and fear $(W=47781, p=.837, d=$ $\left.0.005, \mathrm{BF}_{10}=0.09\right)$.

\section{Does COVID-19-relatedness moderate outcome measures?}

Self-reported intrusive thoughts. The same 2 × 2 × 2 mixed ANOVA as above on self-reported intrusive thoughts revealed no significant Time by Condition interaction $(p=.866)$, or Time by COVID-19-relatedness $(p=.894)$ nor a three-way interaction $(p=.200)$.

Intrusion monitoring. A 2 (Condition, Prosocial vs. Proself) X 2 (COVID-19-relatedness, COVID19-related vs. COVID-19-unrelated) ANOVA on intrusion frequency revealed no significant main effects $(p s>0.146)$ nor an interaction $(p=.070)$.

Subjective COVID-19 related worry and fear. The same 2 X 2 ANOVA revealed no main effects ( $p s$ $>.053)$ nor an interaction $(p s>.130)$ for COVID-19-related subjective worry/fear.

Non-Preregistered Exploratory Analyses: Excluding only Bots and Duplicates $(N=1317)$ :

We repeated our pre-registered analyses excluding bots, duplicates and prosocial opt-out participants. In the COVID-19-Related conditions, this resulted in 297 participants in the prosocial condition and 350 participants in the proself condition. In the COVID-19-Unrelated conditions, this resulted in 313 participants in the prosocial condition and 357 participants in the proself condition.

Positive psychological outcomes. Consistent with our pre-registered predictions, participants in the prosocial (vs. proself) condition reported higher average scores of positive psychological outcomes in 
the COVID-19- related conditions $(W=35097, p<.001, d=0.60)$ and in the COVID-19- unrelated conditions $(W=23651, p<.001, d=1.12)$.

Positive affect. Consistent with our pre-registered predictions, ANCOVA controlling for baseline showed that prosocial participants reported higher post-task positive affect compared to proself participants in the COVID-19-related conditions $(F(1,644)=14.43, p<.001, d=0.30)$ and in the COVID-19-unrelated conditions $(F(1,667)=31.13, p<.001, d=0.43)$.

Negative affect. In contrast to our pre-registered hypotheses, the ANCOVA on post-task negative affect showed there were no significant differences between proself and prosocial spending in the COVID-19-related conditions, $F(1,644)=1.39, p=.238, d=0.09$, nor in the COVID-19-unrelated conditions: $F(1,667)=0.73, p=.392, d=0.07$.

\section{Experiments 1 and 2 Regression analyses with individual difference variables}

In Experiment 1, we unexpectedly found participants in the prosocial condition had significantly higher score on their baseline sleepiness, DASS-21 and TCAQ scores than the participants from the non-prosocial condition (Table S6). These baseline differences could be due to sampling errors, given that such differences were absent in Experiment 2. Indeed, in Experiment 2, none of the individual difference variables differed significantly between the two conditions within the COVID19-related and COVID-19-unrelated conditions (Table S7).

Given that individual differences could contribute to observed effects in affect changes, we conducted non-preregistered linear regression analyses using 1) condition and 2) all individual difference variables as predictors on positive/negative affect change scores (post-task minus baseline), self-reported intrusions change, intrusion frequency, subjective worry and fear for Experiments 1 and 2 .

Results of these regression analyses confirmed results from pre-registered ANCOVAs: after controlling individual difference variables in the regression model, condition remained to be a 
significant predictor for positive $(p=.011)$ and negative affect change scores $(p<.001)$ in Experiment 1 (Table S8). For Experiment 2, condition remained as a significant predictor for positive affect change scores in both COVID-19-related $(p<.001)$ and COVID-19-unrelated $(p<.001)$ conditions (Table S9). Condition became as a significant predictor for subjective worry in COVID19-related ( $p=.014)$ condition, but not in COVID-19-unrelated $(p=.533)$ condition. For Experiment 2, condition remained an unsignificant predictor for negative affect change scores in both COVID19-related $(p=.186)$ and COVID-19-unrelated $(p=.646)$. For both Experiment 1 and Experiment 2, after controlling all individual difference variables, the condition remained an unsignificant predictor for self-reported intrusions change, intrusion frequency and fear $(p s>.05)$. Correlational coeffiencies between individual difference questionnaire scores and outcomes measures are provided in Tables S10-12.

Experiments 1 and 2 Non-Preregistered Exploratory Analyses:

Depression/anxiety/stress levels and prosocial behavior's emotional benefits. We examined whether prosocial behavior's emotional benefits in positive affect may depend on participants' mood disturbances, as assessed in the DASS-21 questionnaire. Combining participants from both Experiments 1 and 2 (total $N=1623$ ), we conducted linear regression analyses using condition (prosocial vs. non-prosocial), depression/anxiety/stress scores and their interactions to predict positive affect change. While conditions remained to be a significant factor predicting positive affect, none of the interactions were significant $(\beta \mathrm{s}=-0.006-0.021, p \mathrm{~s}: .092-.695)$, suggesting that mood disturbances did not impact prosocial behavior's emotional benefits in increasing positive affect.

Effect of Empathetic concern and perception of COVID-19 impact on prosocial behavior's emotional benefits. Prompted by an anonymous reviewer's comments, we examined whether individual differences in empathetic concerns and perceptions of COVID-19 impact moderate the emotional benefits of prosocial acts in Experiment 1 and 2. First, we conducted correlational analyses between 
individual differences in empathetic concerns and positive affect enhancement (post-task minus pretask average positive affect scores) in the Prosocial condition. In both Experiments 1 and 2, the correlation was not significant, $r=0.11, p=.13$ for Experiment 1, $r=0.07, p=.12$ for Experiment 2, suggesting that at least among participants who chose to engage a prosocial act, empathy was not associated with positive affect enhancement.

To further understand whether individual differences in empathetic concerns may moderate the emotional rewards of prosocial vs. proself actions, we next used Condition (prosocial vs. nonprosocial), Empathetic Concern and their interaction to predict positive affect enhancement in a linear regression model. In Experiment 1, we found that the interaction was significant, $b=0.04, p$ $=.048$, which was driven by higher slopes in the prosocial $(b=0.02,95 \% \mathrm{CI}[-0.01,0.05])$ than in the non-prosocial condition $(b=-0.02,95 \%$ CI $[-0.04,0.01])$. Inspecting Figure S1A suggests that within the prosocial condition (blue color), individuals with high empathy levels reported higher positive affect from their prosocial act. In contrast, in the proself condition (orange color), individuals with high empathy levels reported lower positive affect from their proself act. Although this interaction was significant, neither relationship within the specific conditions was significant, as the $95 \%$ CIs overlapped with zero. In Experiment 2, however, the interaction was not significant, $b=$ $-0.003, \mathrm{p}=.743$ (Figure S1C).

Thus, across our two experiments, the results are inconclusive: while Experiment 1 suggests that people with high empathy did benefit more from their prosocial acts, Experiment 2 did not replicate this pattern. Given that our studies were not designed to test this specific research question, and the present analyses were not pre-registered, we concluded that future research is needed to address this question.

We next investigated how perception of COVID-19 impact moderate the emotional benefits of prosocial behavior. First, we tested whether reports of COVID-19 impact were associated with 
happiness gains from pre- to post-task happiness in the prosocial conditions. Results showed that baseline perceptions of COVID-19 impact were positively correlated with positive affect enhancement in both Experiment $1, r=.16, p=.04$, and in Experiment $2, r=.28, p<.001$. These correlational analyses suggested that among participants who opted-in in the prosocial condition, higher baseline perceptions of COVID-19 impact were associated with higher emotional benefits of prosocial engagement.

We next repeated the linear regression analyses using baseline perception of COVID-19 impact, condition, and their interactions to predict positive affect enhancement. In Experiment 1, the interaction was not significant, $b=-0.13, p=.115$ (Figure S1B. In Experiment 2, the interaction was not significant, $b=0.07, p=.155$ (Figure S1D). Together, these exploratory analyses suggest that baseline perceptions of COVID-19 impact did not influence the emotional benefits of prosocial behavior. Again, the present studies were not designed to test these questions, and so the samples may be underpowered. 


\section{References}

Lovibond, P. F., \& Lovibond, S. H. (1995). The structure of negative emotional states: Comparison of the Depression Anxiety Stress Scales (DASS) with the Beck Depression and Anxiety Inventories. Behavior Research and Therapy, 33(3), 335-343.

NCHS (2020). Household Pulse Survey - COVID-19. Retrieved June 03, 2020, from https://www.cdc.gov/nchs/covid19/pulse/mental-health.html 
Supplementary Figure 1
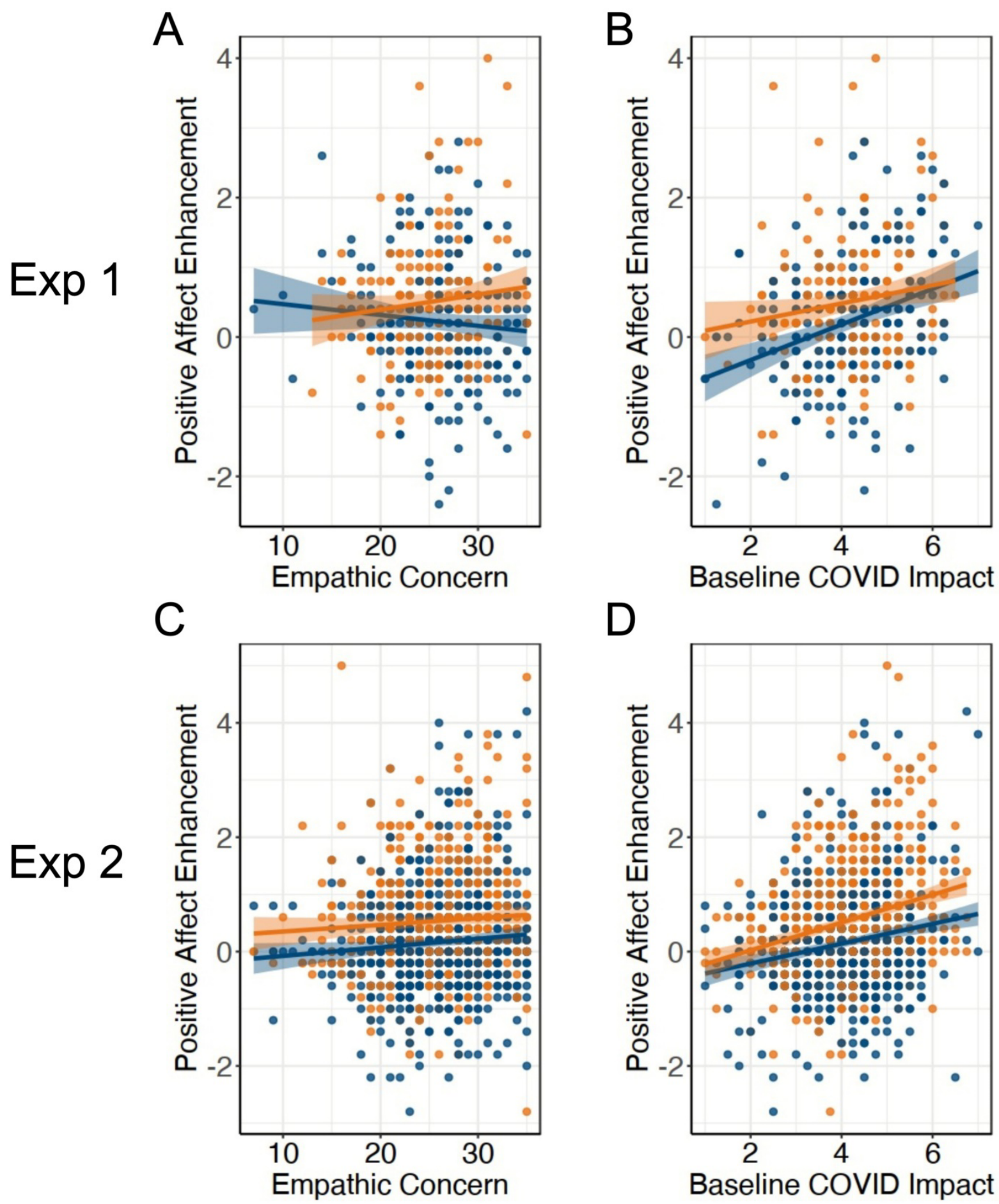

$D$

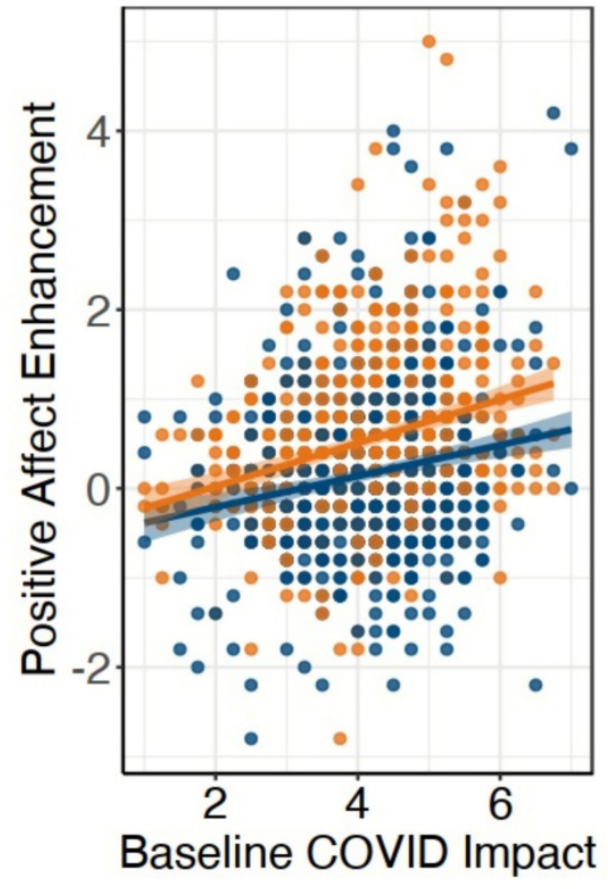




\section{Supplementary Tables}

Table S1. Experiment 1 Prosocial condition (based on $n=213$ ) Opt-in vs. Opt-out participants' demographic information, average baseline ratings of COVID-19's psychological impact, as well as individual difference scores based on questionnaires, Mean \pm S.E. (S.D.), $p$ values from $t$-tests or equivalent Mann-Whitney $U$ tests).

\begin{tabular}{|c|c|c|c|}
\hline & $\begin{array}{c}\text { Opt-in } \\
(n=181)\end{array}$ & $\begin{array}{l}\text { Opt-out } \\
(n=32)\end{array}$ & $p$ \\
\hline Age (S.D.) in years & $26.05 \pm 0.42(5.65)$ & $28.16 \pm 1.09(6.18)$ & .073 \\
\hline Gender (Female \%) & 42.54 & 28.12 & \\
\hline COVID-19 Infectiousness & $5.91 \pm 0.09(1.22)$ & $5.59 \pm 0.30(1.70)$ & .580 \\
\hline COVID-19 Death Rate & $3.36 \pm 0.11(1.54)$ & $3.38 \pm 0.28(1.56)$ & .900 \\
\hline COVID-19 Possibility of Contraction & $4.34 \pm 0.11(1.48)$ & $4.12 \pm 0.29(1.62)$ & .475 \\
\hline Positive Mood (Past 7 Days) & $3.48 \pm 0.10(1.28)$ & $3.45 \pm 0.25(1.40)$ & .956 \\
\hline Negative Mood (Past 7 Days) & $3.58 \pm 0.10(1.38)$ & $2.81 \pm 0.23(1.28)$ & .005 \\
\hline Physical Health Concerns & $3.90 \pm 0.11(1.53)$ & $4.06 \pm 0.31(1.74)$ & .706 \\
\hline Negative Impact on Work/Social Life & $5.65 \pm 0.10(1.38)$ & $5.44 \pm 0.29(1.66)$ & .680 \\
\hline Negative Impact on Mental Health & $3.76 \pm 0.11(1.50)$ & $3.44 \pm 0.25(1.44)$ & .314 \\
\hline Current Distress Level & $3.59 \pm 0.11(1.44)$ & $2.94 \pm 0.24(1.34)$ & .028 \\
\hline Intrusive Thoughts (Past 7 Days) & $3.53 \pm 0.09(1.24)$ & $3.11 \pm 0.21(1.20)$ & .083 \\
\hline Depression (DASS-21) & $6.65 \pm 0.35(4.75)$ & $5.38 \pm 0.84(4.74)$ & .129 \\
\hline Anxiety (DASS-21) & $3.17 \pm 0.25(3.41)$ & $2.25 \pm 0.54(3.04)$ & .086 \\
\hline Stress (DASS-21) & $6.48 \pm 0.33(4.50)$ & $4.53 \pm 0.78(4.43)$ & .014 \\
\hline TCAQ & $77.45 \pm 1.17(15.71)$ & $83.25 \pm 3.37(19.06)$ & .072 \\
\hline Empathetic Concern (IRI) & $25.41 \pm 0.34(4.62)$ & $24.00 \pm 0.94(5.29)$ & .164 \\
\hline Perspective Taking (IRI) & $25.46 \pm 0.38(5.10)$ & $24.97 \pm 1.08(6.09)$ & .539 \\
\hline Personal Distress (IRI) & $18.86 \pm 0.34(4.63)$ & $17.75 \pm 0.91(5.16)$ & .490 \\
\hline
\end{tabular}

Note: DASS-21: Depression, Anxiety Stress Scale-21 item version. TCAQ: Thought Control Ability Questionaire. IRI: Interpersonal Reactivity Index. 
Table S2. Experiment 2, Prosocial conditions (including opt-in and opt-out, $n=652$ ), Opt-in versus Opt-out participants' sample demographic information, average baseline ratings of COVID-19's psychological impact, as well as individual difference scores based on questionnaires from the COVID-19-related and COVID-19-unrelated conditions (Mean \pm S.E. (S.D.)), $p$ values from $t$-tests or equivalent Mann-Whitney $U$ tests).

\begin{tabular}{|c|c|c|c|c|c|c|}
\hline & \multicolumn{3}{|c|}{ COVID-19-related Prosocial } & \multicolumn{3}{|c|}{ COVID-19-unrelated Prosocial } \\
\hline & $\begin{array}{l}\text { Prosocial Opt-in } \\
\quad(n=282)\end{array}$ & $\begin{array}{l}\text { Prosocial Opt-out } \\
(n=48)\end{array}$ & $p$ & $\begin{array}{l}\text { Prosocial Opt-in } \\
\quad(n=288)\end{array}$ & $\begin{array}{l}\text { Prosocial Opt-out } \\
(n=34)\end{array}$ & $p$ \\
\hline Age (S.D.) & $25.74(6.37)$ & $26.88(7.10)$ & .368 & $26.99(6.27)$ & $26.15(5.58)$ & .549 \\
\hline Gender (Female \%) & 48.58 & 25.00 & & 53.12 & 32.35 & \\
\hline COVID-19 Infectiousness & $5.92 \pm 0.08(1.29)$ & $5.40 \pm 0.25(1.70)$ & .053 & $6.01 \pm 0.07(1.13)$ & $5.68 \pm 0.29(1.70)$ & .594 \\
\hline COVID-19 Death Rate & $3.68 \pm 0.09(1.58)$ & $3.77 \pm 0.24(1.67)$ & .710 & $3.78 \pm 0.09(1.59)$ & $3.94 \pm 0.25(1.48)$ & .389 \\
\hline COVID-19 Possibility of Contraction & $4.25 \pm 0.09(1.58)$ & $4.52 \pm 0.27(1.89)$ & .229 & $4.32 \pm 0.09(1.56)$ & $3.47 \pm 0.26(1.50)$ & .004 \\
\hline Positive Mood (Past 7 Days) & $1.76 \pm 0.06(1.06)$ & $2.21 \pm 0.20(1.40)$ & .038 & $1.76 \pm 0.07(1.14)$ & $2.03 \pm 0.20(1.17)$ & .058 \\
\hline Negative Mood (Past 7 Days) & $3.69 \pm 0.08(1.37)$ & $3.73 \pm 0.22(1.49)$ & .829 & $3.79 \pm 0.08(1.40)$ & $3.66 \pm 0.25(1.43)$ & .774 \\
\hline Physical Health Concerns & $3.46 \pm 0.09(1.49)$ & $3.67 \pm 0.22(1.51)$ & .213 & $3.58 \pm 0.09(1.52)$ & $3.26 \pm 0.28(1.62)$ & .385 \\
\hline Negative Impact on Work/Social Life & $5.85 \pm 0.09(1.43)$ & $5.44 \pm 0.24(1.66)$ & .074 & $5.74 \pm 0.08(1.44)$ & $5.21 \pm 0.30(1.77)$ & .096 \\
\hline Negative Impact on Mental Health & $3.72 \pm 0.10(1.61)$ & $3.46 \pm 0.23(1.60)$ & .275 & $3.58 \pm 0.09(1.57)$ & $3.38 \pm 0.25(1.48)$ & .563 \\
\hline Current Distress Level & $3.49 \pm 0.09(1.51)$ & $3.56 \pm 0.20(1.38)$ & .721 & $3.53 \pm 0.09(1.46)$ & $3.62 \pm 0.26(1.50)$ & .584 \\
\hline Intrusive Thoughts (Past 7 Days) & $3.47 \pm 0.07(1.16)$ & $3.10 \pm 0.17(1.18)$ & .055 & $3.47 \pm 0.07(1.19)$ & $3.23 \pm 0.19(1.08)$ & .263 \\
\hline Depression (DASS-21) & $6.07 \pm 0.31(5.21)$ & $6.67 \pm 0.78(5.42)$ & .429 & $6.02 \pm 0.30(5.13)$ & $5.00 \pm 0.96(5.58)$ & .097 \\
\hline Anxiety (DASS-21) & $2.87 \pm 0.21(3.50)$ & $3.46 \pm 0.53(3.69)$ & .337 & $3.06 \pm 0.20(3.43)$ & $2.76 \pm 0.52(3.01)$ & .825 \\
\hline Stress (DASS-21) & $5.94 \pm 0.27(4.53)$ & $5.73 \pm 0.73(5.03)$ & .599 & $6.29 \pm 0.26(4.37)$ & $4.46 \pm 0.72(4.19)$ & .019 \\
\hline TCAQ & $\begin{array}{c}79.57 \pm 1.05 \\
(17.69)\end{array}$ & $\begin{array}{c}80.73 \pm 2.56 \\
(17.75)\end{array}$ & .676 & $\begin{array}{c}78.26 \pm 1.05 \\
(17.76)\end{array}$ & $\begin{array}{l}82.00 \pm 2.76 \\
(16.07)\end{array}$ & .211 \\
\hline Empathetic Concern (IRI) & $25.95 \pm 0.31(5.23)$ & $22.52 \pm 0.81(5.62)$ & $<.001$ & $26.03 \pm 0.31(5.28)$ & $23.53 \pm 0.91(5.33)$ & .008 \\
\hline
\end{tabular}


Note: DASS-21: Depression, Anxiety Stress Scale-21 item version. TCAQ: Thought Control Ability Questionaire. IRI: Interpersonal Reactivity Index. 
Table S3. Experiment 2, Proself conditions (including opt-in and opt-out, $n=664$ ), Opt-in versus Opt-out participants' sample demographic information, average baseline ratings of COVID-19's psychological impact, as well as individual difference scores based on questionnaires from the COVID-19-related and COVID-19-unrelated conditions, (Mean \pm S.E. (S.D.)), $p$ values from $t$-tests or equivalent Mann-Whitney $U$ tests).

\begin{tabular}{|c|c|c|c|c|c|c|}
\hline & \multicolumn{3}{|c|}{ COVID-19-related Proself } & \multicolumn{3}{|c|}{ COVID-19-unrelated Proself } \\
\hline & $\begin{array}{l}\text { Proself Opt-in } \\
(n=202)\end{array}$ & $\begin{array}{l}\text { Proself Opt-out } \\
\quad(n=127)\end{array}$ & $p$ & $\begin{array}{l}\text { Proself Opt-in } \\
\quad(n=185)\end{array}$ & $\begin{array}{l}\text { Proself Opt-out } \\
(n=150)\end{array}$ & $p$ \\
\hline Age (S.D.) & $26.60(6.35)$ & $25.55(6.27)$ & .119 & $26.35(6.01)$ & $25.57(6.33)$ & .179 \\
\hline Gender (Female \%) & 42.08 & 48.03 & & 52.43 & 43.33 & \\
\hline COVID-19 Infectiousness & $5.85 \pm 0.09(1.32)$ & $5.89 \pm 0.12(1.33)$ & .708 & $5.88 \pm 0.10(1.30)$ & $5.75 \pm 0.12(1.47)$ & .580 \\
\hline COVID-19 Death Rate & $3.63 \pm 0.11(1.62)$ & $3.39 \pm 0.13(1.50)$ & .174 & $3.78 \pm 0.10(1.42)$ & $3.57 \pm 0.13(1.55)$ & .159 \\
\hline COVID-19 Possibility of Contraction & $4.33 \pm 0.10(1.41)$ & $4.35 \pm 0.13(1.44)$ & .850 & $4.45 \pm 0.11(1.49)$ & $4.06 \pm 0.13(1.64)$ & .028 \\
\hline Positive Mood (Past 7 Days) & $1.91 \pm 0.09(1.27)$ & $1.93 \pm 0.11(1.20)$ & .573 & $1.98 \pm 0.09(1.25)$ & $1.87 \pm 0.10(1.18)$ & .326 \\
\hline Negative Mood (Past 7 Days) & $3.67 \pm 0.10(1.36)$ & $3.48 \pm 0.11(1.25)$ & .175 & $3.80 \pm 0.10(1.33)$ & $3.57 \pm 0.11(1.40)$ & .141 \\
\hline Physical Health Concerns & $3.60 \pm 0.10(1.36)$ & $3.41 \pm 0.12(1.38)$ & .208 & $3.85 \pm 0.12(1.58)$ & $3.45 \pm 0.12(1.44)$ & .026 \\
\hline Negative Impact on Work/Social Life & $5.64 \pm 0.10(1.45)$ & $5.81 \pm 0.11(1.29)$ & .412 & $5.76 \pm 0.11(1.44)$ & $5.69 \pm 0.13(1.55)$ & .918 \\
\hline Negative Impact on Mental Health & $3.81 \pm 0.11(1.60)$ & $3.46 \pm 0.15(1.64)$ & .050 & $3.73 \pm 0.12(1.61)$ & $3.55 \pm 0.12(1.52)$ & .276 \\
\hline Current Distress Level & $3.51 \pm 0.10(1.35)$ & $3.40 \pm 0.12(1.38)$ & .433 & $3.59 \pm 0.10(1.32)$ & $3.45 \pm 0.11(1.39)$ & .256 \\
\hline Intrusive Thoughts (Past 7 Days) & $3.55 \pm 0.08(1.21)$ & $3.27 \pm 0.10(1.11)$ & .055 & $3.51 \pm 0.09(1.16)$ & $3.32 \pm 0.10(1.23)$ & .144 \\
\hline Depression (DASS-21) & $5.85 \pm 0.37(5.21)$ & $5.33 \pm 0.41(4.67)$ & .516 & $6.21 \pm 0.36(4.83)$ & $5.81 \pm 0.43(5.25)$ & .245 \\
\hline Anxiety (DASS-21) & $2.83 \pm 0.22(3.18)$ & $2.65 \pm 0.26(2.89)$ & .889 & $3.34 \pm 0.27(3.66)$ & $2.87 \pm 0.28(3.39)$ & .190 \\
\hline Stress (DASS-21) & $5.86 \pm 0.31(4.47)$ & $5.68 \pm 0.34(3.88)$ & .989 & $6.49 \pm 0.32(4.41)$ & $5.56 \pm 0.36(4.42)$ & .045 \\
\hline TCAQ & $\begin{array}{c}81.50 \pm 1.22 \\
(17.35)\end{array}$ & $\begin{array}{c}81.87 \pm 1.56 \\
(17.60)\end{array}$ & .957 & $\begin{array}{c}78.06 \pm 1.21 \\
(16.49)\end{array}$ & $\begin{array}{c}81.40 \pm 1.51 \\
(18.47)\end{array}$ & .086 \\
\hline Empathetic Concern (IRI) & $25.67 \pm 0.36(5.07)$ & $25.20 \pm 0.47(5.26)$ & .534 & $26.21 \pm 0.38(5.17)$ & $25.28 \pm 0.39(4.80)$ & .074 \\
\hline
\end{tabular}


Note: DASS-21: Depression, Anxiety Stress Scale-21 item version. TCAQ: Thought Control Ability Questionaire. IRI: Interpersonal Reactivity Index. 
Table S4. Experiment 1 individual difference scores across the two conditions (Mean \pm S.E.) and $p$ values based on prosocial vs. proself comparisons $(n=389)$.

\begin{tabular}{|c|c|c|c|}
\hline Individual difference measurements & Prosocial & Non-prosocial & $p$ \\
\hline TCAQ & $77.41 \pm 1.16$ & $82.30 \pm 1.22$ & .003 \\
\hline \multicolumn{4}{|l|}{ DASS: } \\
\hline Depression & $6.68 \pm 0.35$ & $5.56 \pm 0.36$ & .007 \\
\hline Anxiety & $3.18 \pm 0.25$ & $2.56 \pm 0.23$ & .024 \\
\hline Stress & $6.51 \pm 0.33$ & $5.63 \pm 0.31$ & .046 \\
\hline \multicolumn{4}{|l|}{ IRI: } \\
\hline Empathetic Concern & $25.43 \pm 0.34$ & $26.19 \pm 0.36$ & .064 \\
\hline Perspective Taking & $25.49 \pm 0.38$ & $25.32 \pm 0.35$ & .742 \\
\hline Personal Distress & $18.88 \pm 0.34$ & $18.39 \pm 0.36$ & .459 \\
\hline SSS (Baseline) & $2.87 \pm 0.09$ & $2.60 \pm 0.09$ & .010 \\
\hline SSS (Post-Experiment) & $2.74 \pm 0.08$ & $2.58 \pm 0.08$ & .101 \\
\hline
\end{tabular}

Note: TCAQ: Thought control ability questionnaire; IRI: Interpersonal Reactivity Index; SSS: Stanford Sleepiness Scale. 
Table S5. Experiment 1 Statistics from the regression analyses for post-task positive and negative affect.

\begin{tabular}{|c|c|c|c|c|c|c|c|c|}
\hline \multirow[b]{2}{*}{ Predictors } & \multicolumn{4}{|c|}{ Positive Affect } & \multicolumn{4}{|c|}{ Negative Affect } \\
\hline & Estimate & S.E. & $t$ & $p$ & Estimate & S.E. & $t$ & $p$ \\
\hline Intercept & 1.10 & 0.62 & 1.77 & .077 & -0.17 & 0.53 & -0.32 & .752 \\
\hline TCAQ & $1.56 \mathrm{e}-04$ & 0.004 & 0.04 & .969 & 0.01 & 0.003 & 2.05 & .041 \\
\hline \multicolumn{9}{|l|}{ IRI } \\
\hline Empathetic Concern & -0.01 & 0.01 & -0.88 & .380 & 0.003 & 0.01 & 0.35 & .727 \\
\hline Perspective Taking & 0.003 & 0.01 & 0.32 & .749 & -0.01 & 0.01 & -1.28 & .201 \\
\hline Personal Distress & 0.01 & 0.01 & 0.64 & .524 & 0.01 & 0.01 & 1.10 & .273 \\
\hline PSQI & -0.01 & 0.01 & -0.41 & .680 & -0.03 & 0.01 & -2.82 & .005 \\
\hline \multicolumn{9}{|l|}{ DASS } \\
\hline Depression & 0.01 & 0.01 & 0.87 & .385 & 0.03 & 0.01 & 2.52 & .012 \\
\hline Anxiety & 0.002 & 0.02 & 0.11 & .912 & 0.02 & 0.02 & 1.25 & .213 \\
\hline Stress & -0.003 & 0.02 & -0.22 & .829 & 0.002 & 0.01 & 0.15 & .878 \\
\hline Baseline SSS & 0.02 & 0.04 & 0.51 & .609 & 0.002 & 0.04 & 0.06 & .955 \\
\hline Baseline affect & 0.73 & 0.05 & 15.83 & $<.001$ & 0.52 & 0.04 & 13.09 & $<.001$ \\
\hline Condition & 0.22 & 0.09 & 2.54 & .011 & 0.35 & 0.08 & 4.47 & $<.001$ \\
\hline
\end{tabular}

Note: TCAQ: Thought control ability questionnaire; IRI: Interpersonal Reactivity Index; PSQI: Pittsburgh Sleep Quality Index; DASS:

Depression, Anxiety Stress Scale; SSS: Stanford Sleepiness Scale. 
Table S6. Experiment 1 correlational coefficients matrix among individual difference variables and outcome measures.

\begin{tabular}{|c|c|c|c|c|c|c|c|c|c|c|c|}
\hline & PSQI & TCAQ & $\begin{array}{l}\text { Depressio } \\
\text { n (DASS- } \\
\text { 21) }\end{array}$ & $\begin{array}{c}\text { Anxiety } \\
\text { (DASS- } \\
\text { 21) }\end{array}$ & $\begin{array}{c}\text { Stress } \\
\text { (DASS- } \\
\text { 21) }\end{array}$ & PD (IRI) & PT (IRI) & EC (IRI) & $\begin{array}{c}\text { Positive } \\
\text { Affect } \\
\text { Change }\end{array}$ & $\begin{array}{c}\text { Negative } \\
\text { Affect } \\
\text { Change }\end{array}$ & $\begin{array}{c}\text { Intrusion } \\
\text { Change }\end{array}$ \\
\hline PSQI & 1 & & & & & & & & & & \\
\hline TCAQ & 0.02 & 1 & & & & & & & & & \\
\hline $\begin{array}{l}\text { Depression } \\
\text { (DASS-21) }\end{array}$ & 0.01 & $-0.65^{* * *}$ & 1 & & & & & & & & \\
\hline $\begin{array}{c}\text { Anxiety } \\
\text { (DASS-21) }\end{array}$ & 0.07 & $-0.42 * * *$ & $0.61 * * *$ & 1 & & & & & & & \\
\hline $\begin{array}{c}\text { Stress } \\
\text { (DASS-21) }\end{array}$ & 0.06 & $-0.61 * * *$ & $0.72 * * *$ & $0.69 * * *$ & 1 & & & & & & \\
\hline $\begin{array}{c}\text { PD } \\
\text { (IRI) }\end{array}$ & -0.02 & $-0.62 * * *$ & $0.42 * * *$ & $0.35 * * *$ & $0.41 * * *$ & 1 & & & & & \\
\hline $\begin{array}{c}\text { PT } \\
\text { (IRI) }\end{array}$ & -0.02 & 0.04 & 0.05 & 0.04 & 0.03 & $-0.17 * * *$ & 1 & & & & \\
\hline $\begin{array}{c}\text { EC } \\
\text { (IRI) }\end{array}$ & 0.04 & -0.06 & 0.04 & 0.09 & 0.10 & 0.08 & $0.46^{* * *}$ & 1 & & & \\
\hline $\begin{array}{c}\text { Positive Affect } \\
\text { Change }\end{array}$ & -0.01 & $-0.23 * * *$ & $0.26^{* * *}$ & $0.13 * *$ & $0.19 * * *$ & $0.16^{* * *}$ & -0.01 & -0.02 & 1 & & \\
\hline $\begin{array}{c}\text { Negative } \\
\text { Affect Change }\end{array}$ & $-0.13^{* *}$ & $0.29 * * *$ & $-0.27 * * *$ & $-0.23 * * *$ & $-0.29 * * *$ & $-0.19 * * *$ & -0.02 & $-0.12 *$ & $-0.35 * * *$ & 1 & \\
\hline $\begin{array}{c}\text { Intrusion } \\
\text { Change }\end{array}$ & $-0.12^{*}$ & $0.17 * * *$ & $-0.22 * * *$ & $-0.20 * * *$ & $-0.26^{* * *}$ & $-0.16^{* * *}$ & -0.04 & -0.09 & -0.09 & $0.16^{* * *}$ & 1 \\
\hline
\end{tabular}

Note: TCAQ: Thought control ability questionnaire; IRI: Interpersonal Reactivity Index; PD: Personal Distress; PT: Perspective Taking; EC: Empathic Concern. 
Table S7. Experiment 2 individual difference scores across the four conditions (Mean \pm S.E.) and $p$ values based on prosocial vs. proself comparisons ( $n=1,234$, including proself opt-out participants).

\begin{tabular}{lcccccc}
\hline & & COVID-19-related & & \multicolumn{2}{c}{ COVID-19-unrelated } \\
Individual difference measurements & Prosocial & Proself & $p$ & Prosocial & Proself \\
\hline TCAQ & $79.57 \pm 1.05$ & $81.64 \pm 0.96$ & .094 & $78.26 \pm 1.05$ & $79.56 \pm 0.95$ & .360 \\
DASS: & & & & & \\
Depression & $6.07 \pm 0.31$ & $5.65 \pm 0.28$ & .337 & $6.02 \pm 0.30$ & $6.03 \pm 0.27$ \\
Anxiety & $2.87 \pm 0.21$ & $2.76 \pm 0.17$ & .803 & $3.06 \pm 0.20$ & $3.13 \pm 0.19$ & .975 \\
Stress & $5.94 \pm 0.27$ & $5.79 \pm 0.23$ & .887 & $6.29 \pm 0.26$ & $6.07 \pm 0.24$ & .538 \\
IRI & & & & & \\
$\quad$ Empathetic Concern & $25.95 \pm 0.31$ & $25.49 \pm 0.28$ & .193 & $26.03 \pm 0.31$ & $25.79 \pm 0.27$ & .397 \\
$\quad$ Perspective Taking & $24.95 \pm 0.28$ & $25.65 \pm 0.26$ & .159 & $26.11 \pm 0.29$ & $25.41 \pm 0.27$ & .073 \\
$\quad$ Personal Distress & $18.30 \pm 0.29$ & $18.11 \pm 0.29$ & .710 & $18.83 \pm 0.31$ & $18.34 \pm 0.28$ & .196 \\
Sleepiness (Baseline) & $2.78 \pm 0.07$ & $2.67 \pm 0.07$ & .325 & $2.71 \pm 0.07$ & $2.88 \pm 0.07$ \\
Sleepiness (Post-Experiment) & $2.73 \pm 0.07$ & $2.61 \pm 0.06$ & .247 & $2.62 \pm 0.07$ & $2.74 \pm 0.06$ & .137 \\
\hline
\end{tabular}

Note: TCAQ: Thought control ability questionnaire; IRI: Interpersonal Reactivity Index; SSS: Stanford Sleepiness Scale. 
Table S8. Experiment 2 Statistics from the regression analyses for post-task positive affect scores within the COVID-19-related and COVID-19unrelated conditions $(n=1,234)$.

\begin{tabular}{|c|c|c|c|c|c|c|c|c|}
\hline \multirow[t]{2}{*}{ Predictors } & \multicolumn{4}{|c|}{ COVID-19-related } & \multicolumn{4}{|c|}{ COVID-19-unrelated } \\
\hline & Estimate & S.E. & $t$ & $p$ & Estimate & S.E. & $t$ & $p$ \\
\hline Intercept & 0.02 & 0.44 & 0.05 & .957 & 0.62 & 0.51 & 1.23 & .220 \\
\hline TCAQ & 0.004 & 0.003 & 1.30 & .196 & $-6.24 e-05$ & 0.003 & -0.02 & .985 \\
\hline \multicolumn{9}{|l|}{ IRI } \\
\hline Empathetic Concern & $4.14 \mathrm{e}-04$ & 0.008 & 0.05 & .959 & 0.02 & 0.008 & 2.00 & .046 \\
\hline Perspective Taking & 0.009 & 0.009 & 1.04 & .301 & 0.008 & 0.008 & 0.99 & .322 \\
\hline Personal Distress & $-2.83 \mathrm{e}-05$ & 0.008 & -0.003 & .998 & 0.01 & 0.009 & 1.51 & .133 \\
\hline PSQI & $5.35 \mathrm{e}-0.3$ & 0.01 & 0.48 & .635 & -0.003 & 0.01 & -0.24 & .813 \\
\hline \multicolumn{9}{|l|}{ DASS } \\
\hline Depression & $-7.92 \mathrm{e}-0.4$ & 0.01 & 0.07 & .941 & -0.01 & 0.01 & -1.20 & .231 \\
\hline Anxiety & 0.009 & 0.01 & 0.61 & .540 & 0.03 & 0.01 & 2.26 & .024 \\
\hline Stress & 0.02 & 0.01 & 2.06 & .040 & -0.01 & 0.01 & -0.99 & .323 \\
\hline Baseline SSS & 0.02 & 0.03 & 0.73 & .467 & -0.02 & 0.03 & -0.52 & .604 \\
\hline Baseline Positive Affect & 0.80 & 0.03 & 23.66 & $<.001$ & 0.67 & 0.04 & 18.17 & $<.001$ \\
\hline Condition & 0.31 & 0.07 & 4.31 & $<.001$ & 0.41 & 0.07 & 5.71 & $<.001$ \\
\hline
\end{tabular}

Note: TCAQ: Thought control ability questionnaire; IRI: Interpersonal Reactivity Index; PSQI: Pittsburgh Sleep Quality Index; DASS:

Depression, Anxiety Stress Scale; SSS: Stanford Sleepiness Scale. 
Table S9. Experiment 2 correlational coefficients matrix among individual difference variables and outcome measures in COVID-19-related conditions $(n=611)$

\begin{tabular}{|c|c|c|c|c|c|c|c|c|c|c|c|}
\hline & PSQI & TCAQ & $\begin{array}{l}\text { Depression } \\
\text { (DASS- 21) }\end{array}$ & $\begin{array}{c}\text { Anxiety } \\
\text { (DASS- } \\
\text { 21) }\end{array}$ & $\begin{array}{c}\text { Stress } \\
\text { (DASS- } \\
\text { 21) }\end{array}$ & $\begin{array}{c}\text { PD } \\
\text { (IRI) }\end{array}$ & $\begin{array}{c}\text { PT } \\
(\text { IRI) }\end{array}$ & EC (IRI) & $\begin{array}{c}\text { Positive } \\
\text { Affect } \\
\text { Change }\end{array}$ & $\begin{array}{c}\text { Negative } \\
\text { Affect } \\
\text { Change }\end{array}$ & $\begin{array}{c}\text { Intrusion } \\
\text { Change }\end{array}$ \\
\hline PSQI & 1 & & & & & & & & & & \\
\hline TCAQ & $<.001$ & 1 & & & & & & & & & \\
\hline $\begin{array}{l}\text { Depression } \\
\text { (DASS-21) }\end{array}$ & -0.03 & $-0.60 * * *$ & 1 & & & & & & & & \\
\hline $\begin{array}{c}\text { Anxiety } \\
\text { (DASS-21) }\end{array}$ & -0.02 & $-0.46^{* * *}$ & $0.60 * * *$ & 1 & & & & & & & \\
\hline $\begin{array}{c}\text { Stress } \\
\text { (DASS-21) }\end{array}$ & -0.004 & $-0.59 * * *$ & $0.68 * * *$ & $0.63 * * *$ & 1 & & & & & & \\
\hline $\begin{array}{c}\text { PD } \\
\text { (IRI) }\end{array}$ & -0.002 & $-0.58 * * *$ & $0.40 * * *$ & $0.39 * * *$ & $0.4 * * *$ & 1 & & & & & \\
\hline $\begin{array}{c}\text { PT } \\
\text { (IRI) }\end{array}$ & -0.04 & 0.06 & -0.05 & -0.07 & $<.001$ & $-0.11 * *$ & 1 & & & & \\
\hline $\begin{array}{c}\text { EC } \\
(\text { IRI) }\end{array}$ & -0.04 & -0.06 & -0.01 & -0.01 & 0.07 & 0.08 & $0.53 * * *$ & 1 & & & \\
\hline $\begin{array}{l}\text { Positive Affect } \\
\text { Change }\end{array}$ & -0.01 & $-0.14 * * *$ & $0.19 * * *$ & $0.13 * * *$ & $0.20 * * *$ & $0.09 *$ & 0.01 & 0.03 & 1 & & \\
\hline $\begin{array}{c}\text { Negative Affect } \\
\text { Change }\end{array}$ & 0.06 & $0.22 * * *$ & $-0.26 * * *$ & $-0.15^{* * *}$ & $-0.31 * * *$ & $-0.16^{* * *}$ & -0.05 & $-0.11 * * *$ & $-0.37 * * *$ & 1 & \\
\hline Intrusion Change & -0.05 & $0.10 *$ & $-0.11 * *$ & -0.07 & $-0.13 * * *$ & $-0.11 * * *$ & -0.03 & $-0.14 * * *$ & -0.08 & $0.14 * * *$ & 1 \\
\hline
\end{tabular}


Table S10. Experiment 2 correlational coefficients matrix among individual difference variables and outcome measures in COVID-19-unrelated conditions $(n=623)$.

\begin{tabular}{|c|c|c|c|c|c|c|c|c|c|c|c|}
\hline & PSQI & TCAQ & $\begin{array}{l}\text { Depression } \\
\text { (DASS- 21) }\end{array}$ & $\begin{array}{c}\text { Anxiety } \\
\text { (DASS- } \\
\text { 21) }\end{array}$ & $\begin{array}{c}\text { Stress } \\
\text { (DASS- } \\
\text { 21) }\end{array}$ & $\begin{array}{c}\text { PD } \\
\text { (IRI) }\end{array}$ & $\begin{array}{c}\text { PT } \\
\text { (IRI) }\end{array}$ & $\begin{array}{c}\mathrm{EC} \\
(\text { IRI) }\end{array}$ & $\begin{array}{c}\text { Positive } \\
\text { Affect } \\
\text { Change }\end{array}$ & $\begin{array}{c}\text { Negative } \\
\text { Affect } \\
\text { Change }\end{array}$ & $\begin{array}{c}\text { Intrusion } \\
\text { Change }\end{array}$ \\
\hline PSQI & 1 & & & & & & & & & & \\
\hline TCAQ & -0.03 & 1 & & & & & & & & & \\
\hline $\begin{array}{l}\text { Depression } \\
\text { (DASS-21) }\end{array}$ & $<.001$ & $-0.63 * * *$ & 1 & & & & & & & & \\
\hline $\begin{array}{c}\text { Anxiety } \\
\text { (DASS-21) }\end{array}$ & $<.001$ & $-0.49 * * *$ & $0.61 * * *$ & 1 & & & & & & & \\
\hline $\begin{array}{c}\text { Stress } \\
\text { (DASS-21) }\end{array}$ & -0.02 & $-0.64 * * *$ & $0.64 * * *$ & $0.67 * * *$ & 1 & & & & & & \\
\hline $\begin{array}{c}\text { PD } \\
\text { (IRI) }\end{array}$ & 0.03 & $-0.62 * * *$ & $0.32 * * *$ & $0.34 * * *$ & $0.45^{* * *}$ & 1 & & & & & \\
\hline $\begin{array}{c}\text { PT } \\
\text { (IRI) }\end{array}$ & 0.01 & 0.05 & -0.06 & $-0.05^{*}$ & $-0.08 *$ & -0.11 & 1 & & & & \\
\hline $\begin{array}{c}\text { EC } \\
\text { (IRI) }\end{array}$ & 0.02 & $-0.16^{* * *}$ & 0.01 & 0.01 & $0.11 * *$ & $0.14 * * *$ & $0.48 * * *$ & 1 & & & \\
\hline $\begin{array}{l}\text { Positive Affect } \\
\text { Change }\end{array}$ & 0.01 & $-0.21 * * *$ & $0.16^{* * *}$ & $0.12 * * *$ & $0.15^{* * *}$ & $0.18 * * *$ & 0.06 & $0.13 * * *$ & 1 & & \\
\hline $\begin{array}{c}\text { Negative Affect } \\
\text { Change }\end{array}$ & -0.01 & $0.29 * * *$ & $-0.27 * * *$ & $-0.23 * * *$ & $-0.25 * * *$ & $-0.18 * * *$ & -0.06 & $-0.16 * * *$ & $-0.37 * * *$ & 1 & \\
\hline Intrusion Change & 0.04 & $0.18 * * *$ & $-0.16 * * *$ & $-0.14 * * *$ & $-0.20 * * *$ & $-0.14 * * *$ & -0.02 & $-0.14 * * *$ & -0.06 & $0.19 * * *$ & 1 \\
\hline
\end{tabular}

